\title{
The role of individual variation in marine larval dispersal
}

\section{Gerrit B. Nanninga* and Michael L. Berumen}

Red Sea Research Center, King Abdullah University of Science and Technology, Thuwal, Saudi Arabia

\section{Edited by:}

Xabier Irigoien, King Abdullah

University for Science and

Technology, Saudi Arabia

Reviewed by:

Øyvind Fiksen, University of Bergen,

Norway

Stephen Swearer, University of

Melbourne, Australia

\section{*Correspondence}

Gerrit B. Nanninga, Red Sea

Research Center, King Abdullah

University of Science and

Technology, 4700 KAUST, Thuwal

23955-6900, Saudi Arabia

e-mail: gerrit.nanninga@

kaust.edu.sa
The exchange of individuals among patchy habitats plays a central role in spatial ecology and metapopulation dynamics. Dispersal is frequently observed to vary non-randomly within populations (e.g., short vs. long), indicating that variability among individuals may shape heterogeneity in patterns of connectivity. The concept of context- and condition-dependent dispersal describes the balance between the costs and benefits of dispersal that arises from the interaction of temporal and spatial landscape heterogeneity (the context) with phenotypic variability among individuals (the condition). While this hypothesis is widely accepted in terrestrial theory, it remains questionable to what extent the concept of adaptive dispersal strategies may apply to marine larval dispersal, a process that is largely determined by stochastic forces. Yet, larvae of many taxa exhibit strong navigational capabilities and there is mounting evidence of widespread intra-specific variability in biological traits that are potentially correlated with dispersal potential. While so far there are few known examples of real larval dispersal polymorphisms, intra-specifically variable dispersal strategies may be common in marine systems. Whether adaptive or not, it is becoming apparent that inter-individual heterogeneity in morphology, behavior, condition, and life history traits may have critical effects on population-level heterogeneity in dispersal. Here, we explore the eco-evolutionary causes and consequences of intrinsic and extrinsic variability on larval dispersal by synthesizing the existing literature and drawing conceptual parallels from terrestrial theory. We emphasize the potential importance of larval dispersal polymorphisms in marine population dynamics.

\section{Keywords: condition-dependent dispersal, dispersal costs, dispersal polymorphism, realized connectivity, parental} effects, carry-over effects, habitat fragmentation

\section{INTRODUCTION}

Understanding how, why, and when individuals disperse from their birthplace is a central question in ecology. Dispersal (defined here as the movement of individuals from the natal to a reproductive site) is fundamental to the vast majority of living organisms and ultimately drives gene flow across space and time. Accordingly, dispersal has important ecological and evolutionary consequences for the dynamics and persistence of spatially structured populations (Levins, 1969; Hanski, 1998; Kritzer and Sale, 2004; Ronce, 2007). In the face of global change and widespread habitat degradation, understanding the underlying processes and consequences of dispersal and connectivity are of critical importance for conservation management (Fogarthy and Botsford, 2007; Gibbs et al., 2010).

At the most basic level, the causes and outcomes of dispersal are driven by the interactions of individuals with their environment (Bowler and Benton, 2005). Yet, not each individual in a population will experience, tolerate, and react to its surroundings in the same way, but their responses and performance are based upon past experiences, physiological state, and genetic and phenotypic predispositions (Clobert et al., 2009; Cote et al., 2010). Such inter-individual heterogeneity is increasingly being recognized as a widespread and important feature in ecology (Benton et al., 2006; Bolnick et al., 2011) with potentially far-reaching consequences for dispersal, population dynamics, and species evolution (Bowler and Benton, 2005; Baguette et al., 2013).
In terrestrial dispersal theory, the concept of variable dispersal costs and condition- and context-dependent dispersal has recently received considerable attention (Clobert et al., 2001, 2009, 2012; Bowler and Benton, 2005, 2011; Bonte et al., 2012; Baguette et al., 2013). The fitness of a dispersing organism would thus be a function of the interactions between an individual's phenotype or internal condition and the environment it experiences before, during, and after dispersal (Bernard and McCauley, 2001; Clobert et al., 2009; Tarwater and Beissinger, 2012). Context-dependent effects refer to external environmental factors that may trigger specific dispersal behaviors. Similar individuals may respond differently under different external circumstances. Condition-dependent effects refer to the internal state (condition) or the phenotype of an individual that may affect dispersal. Different individuals may respond differently to the same external circumstances. Context and condition may reciprocally affect each other during dispersal. Depending on the environmental context, inter-individual variability may thus generate heterogeneity in the selective advantage of dispersal, the optimal dispersal trajectory, as well as the performance during and after dispersal (Cote et al., 2010; Bonte et al., 2012). In other words, individual variability in genotype, morphology (e.g., wing-dimorphism in arthropods), personality type (e.g., bold vs. shy), quality (e.g., physiological condition or adaptation capacity), or a combination thereof (Dingle, 1996; Clobert et al., 2009, 2012), may lead to intra-specific variation in the 
propensity and/or ability of individuals to disperse in a heterogenous landscape (Bowler and Benton, 2005; Cote et al., 2010; Bitume et al., 2011). Dispersal polymorphisms (Roff, 1975) have been described in various terrestrial organisms, ranging from arthropods (Zera and Denno, 1997), reptiles (Cote and Clobert, 2012), birds (Duckworth, 2008), mammals (O’Riain et al., 1996), protists (Pennekamp et al., 2014) and plants (Herman and Sultan, 2011). In a meta-analysis of European butterflies, Stevens et al. (2010) compellingly demonstrated that dispersal might be as variable within a species as it is across different species. Such intra-specific dispersal variability was recently shown to have a major impact on estimates of connectivity derived from modeling approaches in terrestrial systems. Palmer et al. (2014) convincingly demonstrated that ignoring within-species variability in models of inter-patch connectivity may lead to poor estimates of the frequency of rare, but often critical, dispersal events. The authors conclude that their results are probably equally relevant for marine systems.

Research on marine larval dispersal and metapopulation connectivity has increased considerably over the past two decades, owing in large parts to the importance of these processes for the implementation of spatial management strategies (Jones et al., 2009; Gaines et al., 2010; Hixon, 2011). Yet, there is a profound bias in the literature on adaptive dispersal polymorphisms toward terrestrial species and the concept remains less well explored in the marine realm (Sotka, 2012). Recent work has highlighted the ubiquity of intra-specific variability in phenotypes and individual condition among larvae and recruits of marine organisms (Marshall and Keough, 2003, 2008) and the potential impact of these differences on the regulation of marine population dynamics (e.g., Allen and Marshall, 2010; Shima and Swearer, 2010; Burgess and Marshall, 2011; Marshall and Morgan, 2011; Burgess et al., 2012). Here we aim to place marine larval dispersal in the framework of context- and condition-dependent dispersal (Bowler and Benton, 2005; Clobert et al., 2009; Gibbs et al., 2010; Bonte et al., 2012) and discuss to what extent concepts developed in the terrestrial literature may be applicable to marine systems. This paper is not meant to be an exhaustive review of all the involved topics-there are excellent recent accounts (e.g., maternal effects: Marshall et al., 2008; connectivity: Cowen and Sponaugle, 2009; phenotype-environment mismatches: Marshall et al., 2010; linked life-history stages: Marshall and Morgan, 2011; dispersal costs: Bonte et al., 2012; dispersal ecology: Clobert et al., 2012)—but rather it is meant to serve as a synthesis of recently emerging and resurgent concepts in the regulation of marine metapopulation connectivity that have so far received comparatively little attention.

\section{MARINE vs. TERRESTRIAL DISPERSAL}

The obvious physical differences between air and water, and the consequences thereof for organisms inhabiting both media, have led to a separation of marine and terrestrial ecology into largely discrete disciplines (Dawson and Hamner, 2008). Yet, careful comparisons across realms can be a valuable tool to understand and tease out universal environmental rules that determine ecological processes (Webb, 2012). Giving consideration to conceptual cross-discipline similarities-even if they are not unequivocal—may provide impulses for new research avenues. In the context of dispersal, the main characteristic distinguishing most marine from terrestrial organisms is a fundamental difference in life history strategies. Most terrestrial species have relatively simple life histories and dispersal is often undertaken by well-developed individuals (Carr et al., 2003). Marine species, in contrast, are often characterized by external fertilization and the production of large numbers of small, pelagic and potentially dispersive eggs and larvae (Sale et al., 2006). Due to the strong influence of transport mediated by convective forces, the spatial scales of dispersal in the sea are hence generally thought to exceed those on land (Carr et al., 2003; Kinlan and Gaines, 2003). The general shape of the dispersal kernel (a probability function of dispersal distance), however, was recently shown to essentially resemble that of many terrestrial species in several marine organisms: a leptokurtic probability distribution with the mode around the origin and a "fat tail" of variable dispersal distances (Buston et al., 2011; Almany et al., 2013; D’Aloia et al., 2013; Lowe and McPeek, 2014). The selective advantage of staying near the natal site thus appears to be high in both realms (see Section Costs of dispersal). The underlying processes leading to the observed patterns, on the other hand, may differ profoundly.

Much of the theoretical progress in dispersal research in terrestrial systems has been achieved by the mechanistic partitioning of dispersal into its three successive stages: emigration, transfer, and settlement (Lidicker and Stenseth, 1992; Baguette and Van Dyck, 2007; Gibbs et al., 2010). In a terrestrial metapopulation context, emigration (or philopatry) is often treated as a decision by the dispersing individual and transfer involves the active movement of organisms through unsuitable habitat. It is hence questionable whether this conceptual approach is suitable for marine systems, where dispersal is driven to large extents by external, stochastic forces. Nonetheless, we argue that various dispersal concepts from terrestrial ecology can be adopted—or should at least be examined-in marine systems to advance our understanding of the processes that drive variation in larval dispersal. It has long been established that larvae of a wide range of marine taxa are far from passive particles. Instead they possess well-developed behavioral and navigational capacities that interact with physical transport processes to alter dispersal outcomes (e.g., fishes: Stobutzki and Bellwood, 1997; Atema et al., 2002; crustaceans: Jeffs et al., 2003, 2005; Radford et al., 2007; corals: Raimondi and Morse, 2000; Vermeij et al., 2010; sponges: Abdul Wahab et al., 2011). While thus there is little doubt that dispersal is not entirely neutral, we still lack a thorough understanding of the relative importance of larval behavior over extrinsic forces on dispersal trajectories.

\section{SOURCES OF INDIVIDUAL VARIATION}

At the most basic level, dispersal variability among individuals is driven by extrinsic (stochastic) and intrinsic (quality- or traitbased) factors (Lowe and McPeek, 2014). The combination of small offspring size with strong physical forcing in marine systems has led to a focus on neutral processes to explain larval dispersal and gene flow in marine systems, i.e., oceanography and environmental factors (e.g., Cowen et al., 2006; White et al., 
2010; Nanninga et al., 2014). The obvious effects of stochastic forces on minute, undeveloped individuals clearly generate strong neutral variation in larval dispersal. Due to spatially stratified currents, for instance, identical larvae may end up in vastly different places if they are released even small distances from one another (Vikebø et al., 2005). While there is little doubt about the paramount importance of extrinsic drivers of larval dispersal variation, we also need a more thorough focus on intrinsic drivers and a better understanding of the relative importance of neutral vs. non-neutral factors in regulating individual dispersal trajectories (Lowe and McPeek, 2014).

Polymorphism in dispersal related biological traits may be adaptive or non-adaptive. Variability in offspring size around a population mean, for instance, may be non-adaptive if stochasticity in resource availability or external stressors through time affect maternal allocation to progeny (Fox and Czesak, 2000; see Section Parental effects). However, phenotypic variation is commonly non-random within a population (Ronce, 2007). A single phenotype is unlikely to perform well in all environmental conditions. Metapopulation theory thus predicts that there should be a selective advantage in plastic dispersal strategies in variable environments or habitats near their carrying capacity (Clobert et al., 2001; Bonte et al., 2010). If the future environment of offspring is unpredictable, it may be beneficial for parents to hedge their bets by producing variable phenotypes that differ from one another in dispersal related traits (Crean and Marshall, 2009; Knott and McHugh, 2012) (Figure 1).

Another source of variation in larval dispersal may be shortterm environmental stochasticity affecting individual condition. Past experience and adaptive responses to a variable environment may thus cause variability in the internal state of individuals (e.g., gut fullness, energy reserves), which in turn affects behavioral strategies during dispersal (Fiksen and Jørgensen, 2011; Jørgensen et al., 2013) (Figure 1). Behavioral responses to external cues (e.g., predators, food) are tightly linked to physical oceanography and small variations in vertical migration, for instance, may have vast consequences for dispersal trajectories (Fiksen et al., 2007; Vikebø et al., 2007).

In either case-evolved dispersal strategies or variable behavioral trade-offs-individual-level adaptations have strong effects on emergent population-level properties such as gene flow, demographic connectivity, species distribution, persistence, and resilience (Jopp and Reuter, 2005) (Figure 1). For instance, dispersal may enhance phenotypic plasticity within a species or population, when phenotypic variation is maintained by dispersal among habitats with variable environmental conditions (Zhang, 2006; Stamps, 2007). Long distance dispersal may thus favor individuals with high levels of plasticity, or alternatively, plasticity may evolve as a function of dispersal scale (as habitat differentiation tends to increase with spatial distance) (Sotka, 2012) (feedback loop 1, Figure 1). On evolutionary scales, phenotypic variability among individuals may affect dispersal strategies, while at the same time dispersal may affect and maintain such phenotypic variability (Stamps, 2007) (feedback loop 2). It will thus be important to not only understand variability in dispersal related traits (see below), but also the processes that maintain this variability (Lowe and McPeek, 2014).

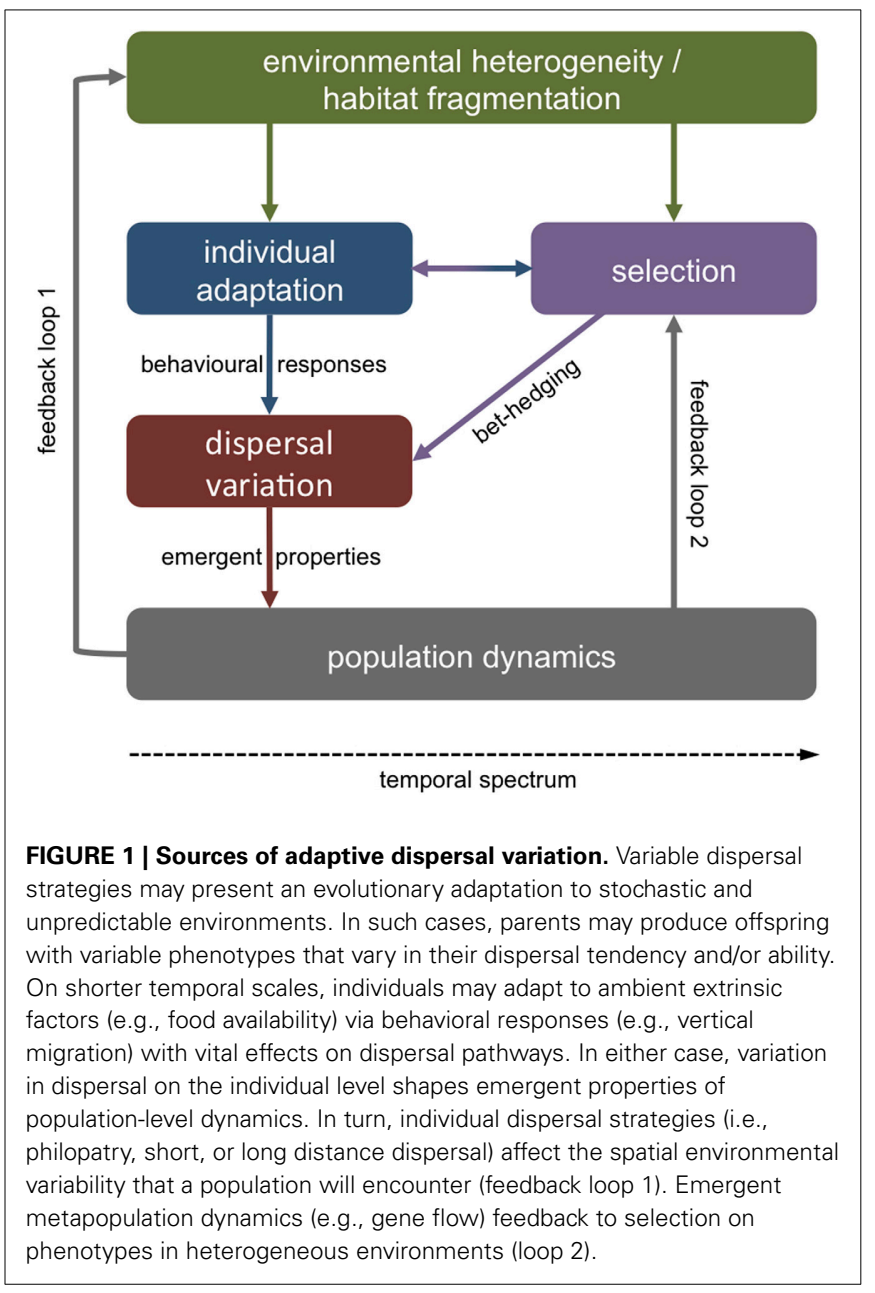

\section{DISPERSAL SYNDROMES}

It is increasingly becoming apparent that dispersal polymorphisms are not random across a population, but often associated with particular phenotypes (Cote et al., 2010; Ronce and Clobert, 2012). Dispersal strategies at the individual level may coevolve with variations in morphological, behavioral, and life history traits forming dispersal syndromes (Clobert et al., 2009; Ronce and Clobert, 2012). The accurate assessment, interpretation and extrapolation of these syndromes is hampered by the often strong covariation among different traits and the intra-specific variability thereof depending on internal and external conditions (Ronce and Clobert, 2012). Nevertheless, the identification of syndromes that could serve as dispersal predictors was shown to be a useful proxy in the forecast of dispersal patterns over a range of terrestrial and semi-terrestrial species (Stevens et al., 2013, 2014). Proxies for dispersal would be especially useful in marine systems, where dispersal itself is exceedingly difficult and costly to measure. There is evidence that dispersal distance in various terrestrial organisms may be related to intra-specific morphological predictors, such as wingspan in birds (Dawideit et al., 2009) and butterflies (Sekar, 2012), leg morphology in salamanders (Lowe and McPeek, 2011), or body size in small mammals (O'Riain et al., 1996; Selonen et al., 2012). Up to this point, 
no specific morphological predictors of dispersal (e.g., larval fin aspect ratios) have been identified and validated in any marine organism [but see Section Costs of dispersal: maternal body size as a potential predictor for natal homing (Beldade et al., 2012)].

Similarly, behavioral traits can have a strong influence on dispersal strategies. Intra-specific variations in personality traits are commonly observed in various taxa and may result in interindividual differences in the propensity toward dispersal (Stamps, 2007; Baguette et al., 2013). "Boldness" in particular is often shown to relate positively to dispersal tendencies (Cote et al., 2010). In coral reef fishes, larval behavior is believed to be an important factor mediating hydrodynamic advection (Kingsford et al., 2002; Paris et al., 2007). Small differences in vertical migration behavior, for instance, can have strong effects on dispersal distance and direction (Sundelöf and Jonsson, 2012). Intrinsic and context-dependent behavioral trade-offs associated with boldness (e.g., food acquisition vs. predator avoidance) may thus have strong effects on growth, survival, and dispersal trajectories (Fiksen and Jørgensen, 2011; Jørgensen et al., 2013). At the same time, low levels of boldness (among other traits) were shown to result in increased post-settlement mortality in a damselfish (Pomacentrus wardi) (Fuiman et al., 2010). By influencing dispersal pathways as well as settlement and post-settlement selection, variations in behavioral traits might present a selective mechanism balancing the costs and benefits of dispersal in marine organisms.

Dispersal syndromes affect the propensity as well as the ability of individuals to disperse in a given context (Bowler and Benton, 2011; Baguette et al., 2013). How far does and individual want to go and how far can it go? Individual dispersal propensity and ability thus determine intraspecific polymorphisms in dispersal (Clobert et al., 2009). While this concept stems from the terrestrial literature, there are several examples of larval dispersal polymorphisms in marine systems.

\section{LARVAL DISPERSAL POLYMORPHISMS POECILOGONY}

Probably the most striking example of a larval dispersal polymorphism is poecilogony, describing the intra-specific variation in larval developmental mode (pelagic, feeding vs. benthic, non-feeding) that has been reported for a number of invertebrate species (Hoagland and Robertson, 1988; Levin and Bridges, 1995; Chia et al., 1996). While it is not fully resolved whether poecilogony represents a genetic polymorphism (Levin et al., 1991), or a plastic response to environmental factors (Krug, 2007; Krug et al., 2012), it clearly has a large impact on patterns of larval dispersal (Knott and McHugh, 2012). In the few real cases of poecilogony described to date, investigators observed two distinct larval morphs with different dispersal potential: (1) small eggs develop into planktotrophic larvae with an obligatory pelagic larval phase, (2) large eggs develop into lecithotrophic larvae that can metamorphose without feeding in the plankton (Vendetti et al., 2012). Poecilogony is believed to present a bet-hedging strategy by parents, providing offspring with variable phenotypes (i.e., long-distance and short-distance types) to match stochastic and unpredictable environments (Knott and McHugh, 2012).

\section{GREGARIOUSNESS}

Another well-documented dispersal polymorphism in marine invertebrates is inter-individual variation in gregariousness (Toonen and Pawlik, 1994, 2001a). Toonen and Pawlik demonstrated in numerous experiments that larvae of the tubeworm Hydroides dianthus differ in their tendency to settle in the presence (aggregators) or absence (founders) of conspecifics (Toonen and Pawlik, 1994, 2001a,b). In addition to specific settlement preferences, aggregators stay competent to settle for longer time periods than do founders. This variability among sibling larvae probably has strong emergent effect on the patterns of dispersal in $H$. dianthus, resulting in the colonization of nearby, uninhabited habitats by founders and potential long-distance connectivity with already occupied habitats by aggregators (Toonen and Pawlik, 1994, 2001a).

\section{CORAL POLYP CLUSTERING}

More recently, Mizrahi et al. (2014) discovered a potential dispersal polymorphism in a scleractinian coral, Tubastrea coccinea. Larvae of this species usually settle and metamorphose after 3 days in the plankton. As an alternative strategy, planulae were observed to metamorphose into mobile polyps in the plankton and form clusters of different sizes. Singular and clustered polyps exhibited longer pelagic survival than planulae, potentially presenting an adaptation to increase dispersal capacity (Mizrahi et al., 2014).

\section{AMPHIDROMY}

Amphidromy describes the dispersal of eggs and larvae through estuary or marine environments before juveniles return to a freshwater stream (McDowall, 2007, 2010). Marine dispersal, however, is often facultative and some individuals may stay in freshwater for their entire life cycle. Using otolith microchemistry, two recent studies independently identified strong dispersal polymorphisms within different species of freshwater gobies (Hogan et al., 2014; Huey et al., 2014). In both studies, more than $60 \%$ of the sampled individuals completed their entire life cycle within streams, while the remaining $40 \%$ exhibited amphidromous migrations. Hogan et al. (2014) found that in Awaous stamineus, individuals with marine dispersal exhibited clear growth advantages over purely freshwater morphs. These benefits likely persisted into adult life. The authors conclude that different dispersal strategies in A. stamineus are generated by variable cost-benefit ratios of amphidromy vs. retention in the natal stream. While staying within a stream reduces the potential immediate costs of dispersal (see Section Costs of dispersal), marine dispersal confers potential long-term fitness benefits (Hogan et al., 2014).

\section{VARIABILITY IN DISPERSAL TRAITS}

As Toonen and Pawlik (2001a, p. 2450) state, "all larvae are not created equal." While true dispersal polymorphisms have been identified only in a handful of species, the marine literature holds numerous examples of inter-individual variability in traits related to dispersal (Raimondi and Keough, 1990). Virtually any study testing discrete settlement preferences, for instance, involves larvae that readily chose the control treatment (Figure 2). Yet, this variability in larval behavior is rarely discussed in the overall conclusions and most authors simply report a species-wide attraction 


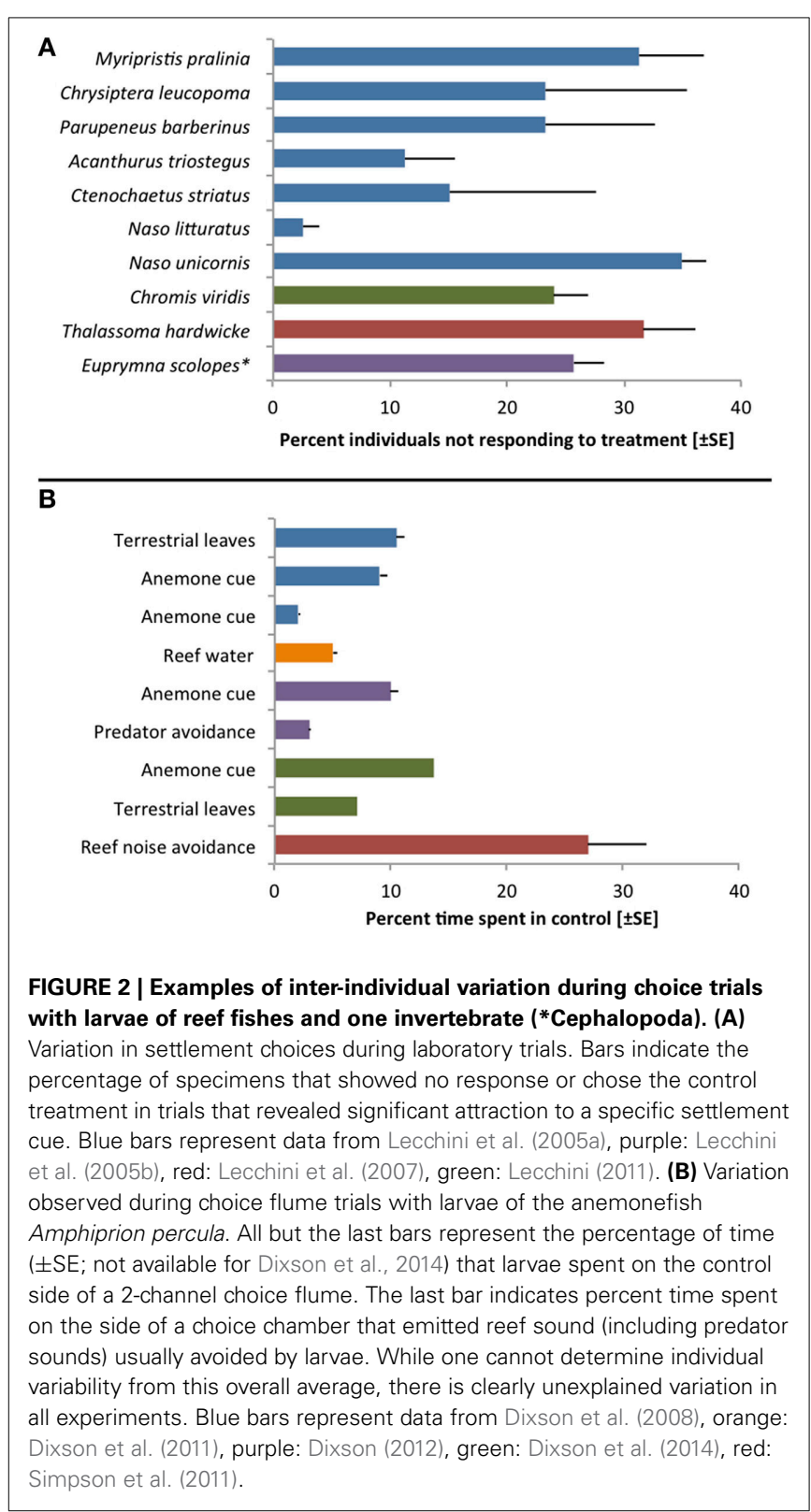

(or repulsion) to specific cues. Rather than representing experimental error or chance, however, individually variable settlement preferences and behaviors may be indicative of important adaptations to stochastic environmental conditions (Toonen and Pawlik, 2001a; Bowler and Benton, 2005; Clobert et al., 2009).

Owing to its potential importance during the dispersal process, swimming abilities of reef fish larvae have received considerable attention over the past two decades (e.g., Stobutzki and Bellwood, 1994, 1997; Fisher et al., 2000; Fisher and Bellwood, 2002). Fisher et al. (2005) found that there is large intra-specific variation (28\%) in critical swimming speeds among larvae of 89 species of reef fishes. These differences could not be explained by body size or residual weight, indicating that there is genuine genetic or maternally induced variability in the ability or propensity toward swimming behavior within populations. When further dissecting

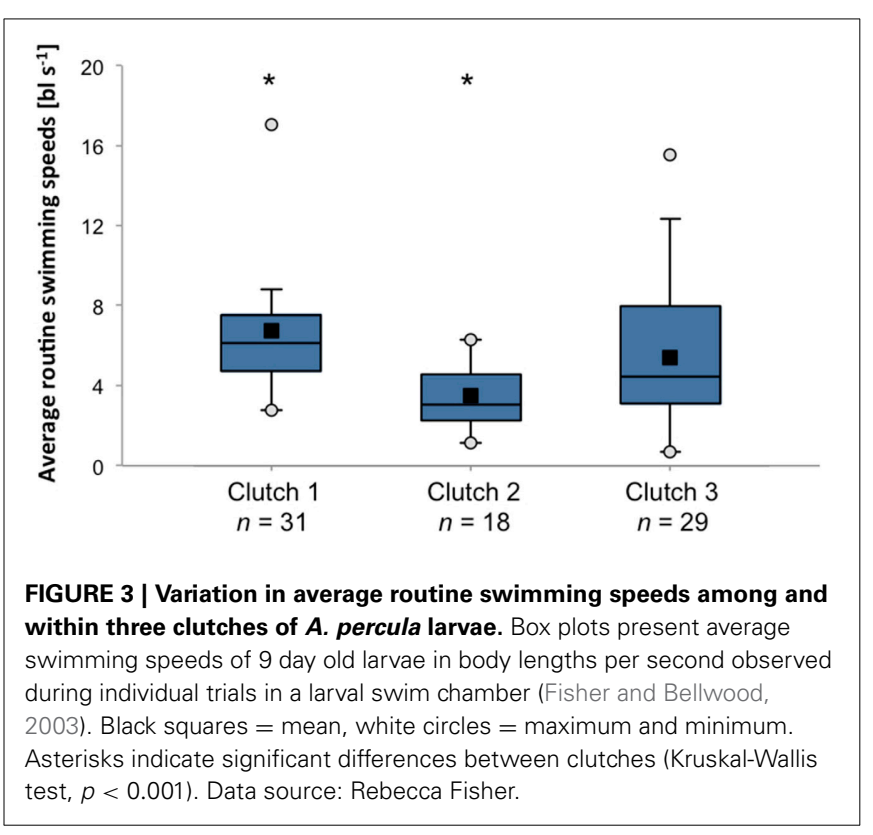

the data from Fisher and colleagues it becomes clear that there is large inter-individual variability in swimming performance even among clutches and among siblings of a single clutch (Figure 3 ). The extent of the capacity to actively maneuver during the pelagic phase has obvious implications for patterns of dispersal (Fisher, 2005; Leis, 2007), and any variation in such behavior is likely to have critical effects on metapopulation connectivity. Similarly, variability in sensory capacities (e.g., olfactory, auditory) will play a vital role in the ability to navigate back to suitable habitats after the pelagic phase. To date, despite its likely critical importance for connectivity patterns, little research has directly focused on inter-individual variation in navigational abilities.

The literature holds many more examples of natural intraspecific variability in traits that are potentially important for dispersal, even though this variability is not always explicitly explored in the respective studies. To discuss all of these examples goes beyond the scope of this review (e.g., boldness: Coleman and Wilson, 1998; hormone levels in eggs and size at hatching: McCormick, 1999; growth rates and larval duration: Searcy and Sponaugle, 2000; ability to delay metamorphosis: Marshall and Keough, 2003), yet clearly, inter-individual phenotypic heterogeneity is ubiquitous in marine organisms and potentially has important emergent consequences at the population/species/community level.

While it is not clear to what extent marine larvae can make choices about their dispersal trajectories, i.e., exhibit dispersal propensities, there are some indications that adaptive dispersal polymorphisms are widespread in larvae of marine organisms. The following line of arguments is based on empirical estimates of larval dispersal in populations of coral reef fishes derived from genetic parentage analysis. (1) Within-patch variability I: Two different species of coral reef fishes (A. percula and Chaetodon vagabundus) at Kimbe Island in Papua New Guinea produced individuals returning to the natal reef as well as larvae dispersing to distant patches (in excess of $30 \mathrm{~km}$ ) within the same cohort 
(Planes et al., 2009; Berumen et al., 2012). While it remains uncertain whether this pattern is a result of mere physical transport or active behavior, the studies do show that there may be within-patch variability in dispersal strategies in a single generation. (2) Within-patch variability II: Around Kimbe Island, certain anemones were shown to regularly produce larvae that return to the island to settle, while other anemones never do. This pattern was consistent over four sampling periods (2005, 2007, 2009, 2011) (Saenz-Agudelo et al., unpublished data). Local adaptation to small-scale environmental heterogeneity may produce within-patch variability in maternal effects on larval phenotypes (see Section Parental effects) with far-reaching consequences for patterns of dispersal. (3) Among-patch variability: Different locations were shown to exhibit specific and persistent patterns of local recruitment between two species of anemonefish with similar life history characteristics (A. percula and A. bicinctus). While Kimbe Island seems to generate consistently high levels of self-recruitment across different generations (Berumen et al., 2012), a coral reef in the Red Sea was shown to exhibit very limited local recruitment over two consecutive years (Nanninga et al., 2014). (4) Intergenerational variability: Individual offspring of the anemonefish $A$. polymnus from the same parent pair were shown to disperse in one generation and return to the natal reef in the next (Saenz-Agudelo et al., 2014). While the mechanisms behind these patterns also remain unclear, it may be an indication of the spatial and temporal variation in condition-dependent dispersal strategies. While these arguments are largely speculative, the existence of different intra-specific dispersal strategies or context-dependent dispersal propensities may have important consequences for the way we view, study and model metapopulation connectivity in marine species. Clearly, adaptive dispersal polymorphisms - if real-are not limited to philopatry vs. long distance dispersal, but present a continuum of dispersal distance strategies determined to large extents also by the ambient oceanographic regime and habitat availability. An understanding of the causes and effects of different dispersal strategies might shed new light on the functioning of marine population dynamics.

\section{LINKED LIFE-HISTORY}

A critical aspect in the concept of variability in larval condition is the interdependence of life history stages. Much of the empirical research pertaining to marine larval dispersal has so far focused on one stage of the process, e.g., settlement. In many marine organisms with complex life histories, however, different life stages may be tightly linked (reviewed in Marshall and Morgan, 2011) and experiences from one stage can carry over to affect performance and survival in subsequent stages (Pechenik, 2006). These carry-over or latent effects may have important ramifications for connectivity and population dynamics, because effects formed before and during dispersal may propagate across several life history stages to affect individual post-settlement and reproductive success (Marshall et al., 2003; Pechenik, 2006; Gagliano et al., 2007; Marshall and Morgan, 2011). Exposure to elevated $\mathrm{CO}_{2}$ during the larval phase, for instance, was shown to result in reduced post-settlement performance (shell growth and size) in different species of bivalves, the effects of which were visible over extended time spans (several months) after the treatment (Hettinger et al., 2012, 2013; Gobler and Talmage, 2013). External factors experienced in one life history stage are thus not independent across the life cycle. Identifying statedependent dispersal behaviors and the selective loss of individuals, as well as the reciprocation of individual experiences with specific life history traits, will be vital for a better understanding of population regulation (Hoey and McCormick, 2004; Hamilton, 2008). To properly assess realized connectivity in metapopulations, we need to understand not only the influence of larval quantities reaching a population, but also individual variation in larval quality (Allen and Marshall, 2010; Burgess and Marshall, 2011).

Offspring size was shown to be an effective predictor of performance over a wide range of marine taxa (Marshall and Keough, 2008) and mortality in larval and settlement-stage fish is believed to be largely driven by size-selective processes (Anderson, 1988; Meekan and Fortier, 1996; Wilson and Meekan, 2002; but see Jørgensen et al., 2013). These size advantages can prevail across different life stages and individuals that exhibit larger size-athatching and/or faster larval growth rates often show higher rates of relative survival upon settlement into the benthic community (Bergenius et al., 2002; Vigliola and Meekan, 2002; McCormick and Hoey, 2004; Macpherson and Raventos, 2005; Hamilton et al., 2008; Dias and Marshall, 2010). Yet, growth-related carryover effects might not always act in one direction, but may be strongly dependent on ontogenetic shifts in selective pressures (Gagliano et al., 2007; Meekan et al., 2010). Growth- and sizeselective processes in the marine environment were shown to be highly variable among closely related species (D'Alessandro et al., 2013), ontogenetically within species (Gagliano et al., 2007; Dias and Marshall, 2010; Kesselring et al., 2012), among microhabitats (Smith and Shima, 2011), and dependent on environmental heterogeneity and competition (Marshall et al., 2006; Johnson, 2008; Johnson and Hixon, 2010). Care should hence be taken when interpreting empirical estimates of size effects on early life history stages, as they might not accurately predict subsequent reproductive patterns.

Overall, different life history stages are clearly not independent and variations in biological traits and physiological condition initiated in one stage can affect the entire dispersal process beyond a single generation (Van Allen and Rudolf, 2013; Burton and Metcalfe, 2014). In the next sections, we explore evidence of how the different stages of marine larval dispersal-the natal environment, departure, transfer, settlement, and post-settlement survival-may affect inter-individual variations in dispersal and vice versa (Figure 4 ).

\section{THE INFLUENCE OF LARVAL VARIABILITY ON CONNECTIVITY NATAL ENVIRONMENT}

The parental and geographic origin of an individual may have long-lasting effects on dispersal behaviors and abilities, settlement habitat preferences, and post-settlement performance. Spatial and temporal heterogeneity in environmental factors among and within habitat patches may thus create important variability in dispersal strategies in marine metapopulations. The influence of the natal environment may be direct (e.g., via imprinting) or indirect (e.g., via maternal effects). 


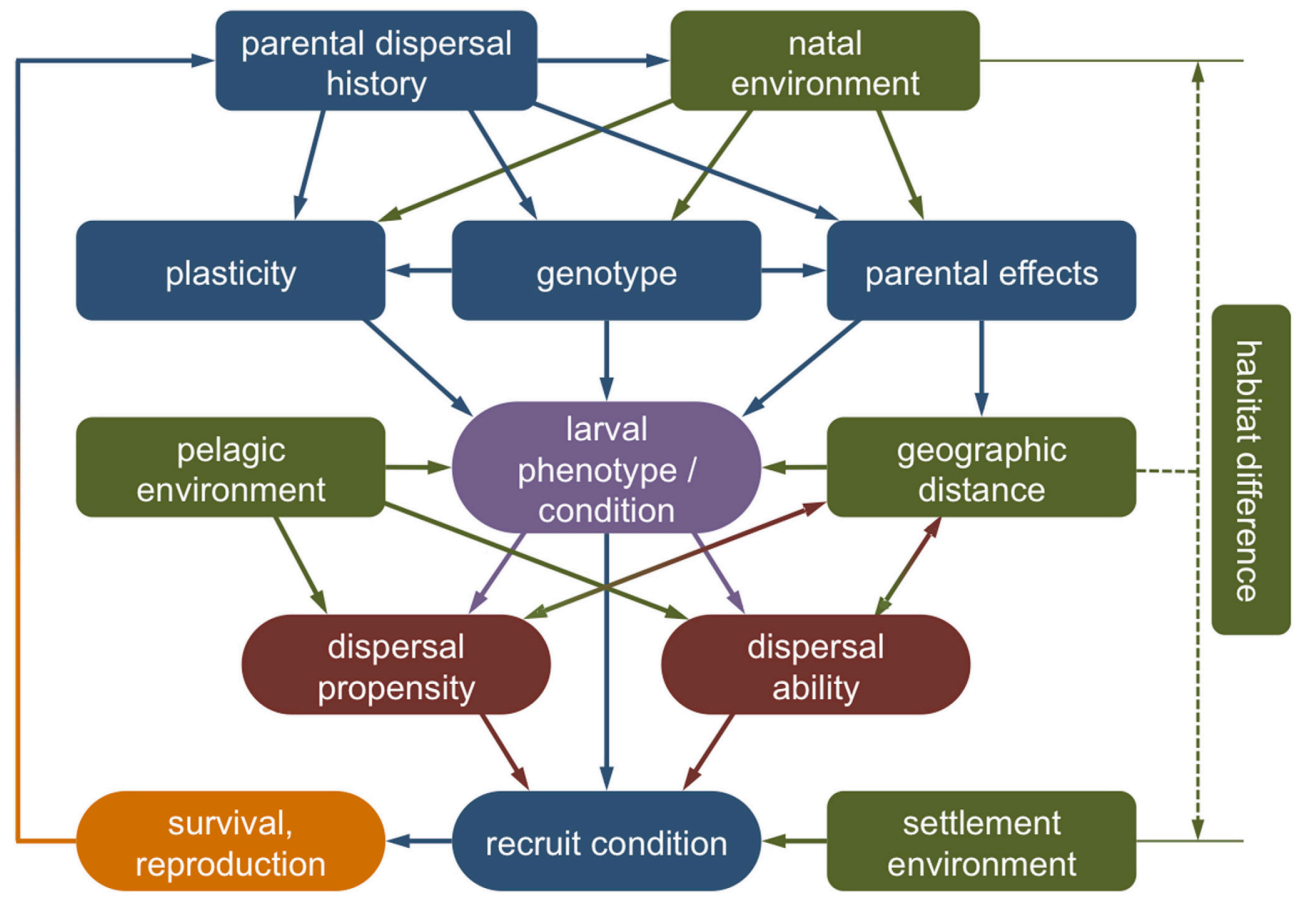

FIGURE 4 | Theoretical framework outlining the causes and consequences of larval dispersal polymorphisms. Intrinsically, the phenotype and condition of a dispersing larva (purple) will be the product of its genotype, plasticity toward environmental variation and parental effects, which in turn are affected by parental history (blue). Extrinsically, the larval phenotype is affected by external conditions experienced in the natal and the dispersal environment (green). The interaction of environmental circumstances (the context) with the genotypic, phenotypic, and physiological state (the condition) shapes the tendency and capacity of an individual to disperse (red). This dispersal strategy (co-)determines the spatial distance of movement, which may feed back to larval and recruit condition via direct and indirect dispersal costs. Carry-over effects of environmental conditions experienced by parents, eggs, or larvae may persist to affect recruit condition and reproductive success (orange).

\section{Direct effects}

Environmental factors experienced in early life stages have the potential to cause strong and irreversible effects on individual phenotypes and long-term fitness (Burton and Metcalfe, 2014). Individual experiences in the natal habitat, for instance, may be an important source of variability in habitat preferences after dispersal. Natal habitat preference induction (NHPI) describes an individual's preference toward settlement habitats that emit similar cues to the natal habitat (Davis and Stamps, 2004), irrespective of the habitat's intrinsic quality (Clobert et al., 2009). NHPI may evolve where individuals consistently gain a selective advantage from remaining near the natal habitat or dispersing to a similar habitat as their parents (Nosil et al., 2005; Marshall et al., 2010, also see Section Costs of dispersal). A possible mechanism by which NHPI can be facilitated in marine organisms with dispersive offspring is "imprinting" to natal environmental conditions during early stages of ontogeny (Immelmann, 1975). In species with benthic eggs, embryos will be subject to natal conditions until hatching occurs. Olfactory imprinting, for instance, was repeatedly shown to facilitate habitat selection in anemonefish (Arvedlund and Nielsen, 1996; Arvedlund et al., 1999; Dixson et al., 2008, 2014). Furthermore, imprinting to natal reef odor was shown to influence reef choice during settlement and may limit dispersal in coral reef fishes (Gerlach et al., 2007). Similar behaviors have long been recognized in salmon, where olfactory imprinting facilitates homing to the natal stream over large distances (Scholz et al., 1976).

Experiences from the natal site might also directly affect individual condition. Environmental factors such as temperature, salinity, UV radiation, oxygen availability, and pollutants are known to have a major influence on egg quality in brooding marine organisms (reviewed in Brooks et al., 1997; Bobe and Labbé, 2010) and populations may rapidly adapt to the local environmental regime (e.g., temperature: Haugen and Vøllestad, 2000). The natal environment may also induce plasticity in hatching, as observed commonly in marine invertebrates with benthic egg masses (Przeslawski, 2004). Predation on eggs, for instance, may cause larvae to hatch early and spend more time in the plankton (Strathmann et al., 2010). Plasticity in hatching is thought to balance the costs of benthic and planktonic development (e.g., egg vs. larval predation) and may be an adaptive response to escape poor local environmental conditions (Miner et al., 2010; Oyarzun and Strathmann, 2011). The natal habitat may thus not only affect habitat selectivity in settlement stage individuals (Davis and Stamps, 2004), but influence egg and larval condition, as well as dispersal potential and competitiveness for habitat choices during settlement (Stamps, 2006; also see Section Settlement). Environmental heterogeneity may hence create spatiotemporal variability in dispersal, thereby potentially linking local scale 
processes to regional scale connectivity (Benard and McCauley, 2008).

\section{Parental effects}

Context- and condition-dependent dispersal starts even before conception. The dispersal history as well as the environmental conditions experienced by parents during their adult life may have paramount effects on the phenotype and condition of the dispersing individual. Non-genetic parental effects are a major source of within-cohort variation (reviewed in Marshall and Uller, 2007; Green, 2008; Marshall et al., 2008). Potential pathways through which parental conditioning can influence offspring phenotype and life histories include female physiology, sperm phenotype, egg composition, allocation of nutritional reserves, and parental care (McCormick, 1999; Green and McCormick, 2005; Green, 2008; Donelson et al., 2009; Crean et al., 2013). The nature of the parental context can thus partially determine the condition and fate of offspring in both adaptive and non-adaptive ways. Where the physiological condition of parents is affected (positively or negatively), parent quality may translate directly into progeny performance through resource and hormonal allocations (McCormick, 2006; Gagliano and McCormick, 2007). In general, larger parents in good condition produce larger, faster growing offspring with higher chances of survival over successive life stages (Berkeley et al., 2004; Green, 2008; Donelson et al., 2009). In contrast, adult exposure to unfavorable conditions can decrease offspring performance up to the point of recruitment and beyond. The negative effects of adult exposure to elevated $\mathrm{CO}_{2}$, for instance, were shown to translate into reduced settlement success in offspring via parental carry-over effects in the green sea urchin Strongylocentrotus droebachiensis (Dupont et al., 2013). Maternal effects may be variable at relatively small spatial scales within populations. George (1994), for example, showed that the size, number, and protein content of eggs differed significantly between sheltered and exposed sites of the same location in the brooding seastar Leptasterius epichlora. Similarly, adults of a coral reef fish, Acanthochromis polyacanthus, from wave-exposed sites were recently shown to possess phenotypes with better swimming capacities than those from sheltered sites (Fulton et al., 2013; Binning et al., 2014). If such adaptations to the local physical regime are passed on to offspring via maternal effects, swimming capacities in larvae from sites with different energetic exposure may vary within patches and populations.

Adaptations to local environmental conditions can in fact be transferred via parental effects, resulting in offspring that are welladapted to the natal environment, as demonstrated repeatedly in terrestrial plant seed dispersal (e.g., Galloway, 2005; Galloway and Etterson, 2007). There is ample evidence for such local phenotypic adaptations in marine invertebrates, where common garden experiments revealed superior performance of local vs. foreign individuals in the same selective environments (reviewed in Sanford and Kelly, 2011). Such transgenerational effects may also be adaptive in changing environments. Parental acclimatization to elevated temperatures and levels of $\mathrm{CO}_{2}$ in different species of coral reef fishes, for example, was shown to mediate some of the negative physiological effects in their offspring when reared in the same environment (Donelson et al., 2012; Miller et al., 2012). It is evident that parental effects play an important role in the spatial and temporal variability in larval condition and phenotype, yet disentangling genetic effects from those of phenotypic plasticity through parental effects remains challenging and warrants further research (Kawecki and Ebert, 2004; Sanford and Kelly, 2011).

Another parental effect that is of paramount importance for larval trajectories is undoubtedly the spawning behavior of adults (Pineda et al., 2007; Cowen and Sponaugle, 2009). Any variation in the location or timing of gamete/larval release may have strong effects on the context-dependent drivers of dispersal experienced by offspring (e.g., food abundance, physical oceanography) and may strongly influence egg/larval trajectories. The study of larval dispersal variability should thus include variations in adult habitat characteristics as well as behavioral strategies.

\section{DEPARTURE}

The largest conceptual discrepancy between terrestrial and marine dispersal theory is probably anchored in the process of departure. As discussed before, departure in a terrestrial context is often treated as a conscious decision by a mobile individual that exhibits active movement among habitats across a matrix of unsuitable habitat. Condition- and context dependent costsbenefit ratios of dispersal can thus cause intra-specific variability in the propensity toward dispersal (Bowler and Benton, 2005; Clobert et al., 2009). This dispersal propensity-in concert with dispersal ability-determines which individuals disperse, how far they move, and which return to or stay near the natal patch (Baguette et al., 2013). In marine systems, dispersal into a pelagic habitat is often obligatory and neutral forces are thought to largely determine dispersal patterns. It hence remains unclear whether dispersal propensities exist in marine organisms. It was shown in several terrestrial species that the tendency of individuals to disperse may be transferred across generations via maternal effects (Tschirren et al., 2007 [birds]), or epigenetic inheritance (Ahlroth et al., 2010 [arthropods]). This ability to plastically adapt the dispersal strategy of the next generation, depending on current environmental conditions and dispersal histories experienced by parents, may be particularly useful in many marine species where offspring are quickly dispersed by currents and "dispersal decisions" must be made early in ontogeny. The described biophysical differences between terrestrial and marine dispersal may also result in a major discrepancy in the concept of dispersal costs.

\section{Costs of dispersal}

The costs of dispersal can either be immediate (i.e., mortality during dispersal), or deferred (i.e., occurring after settlement via carry-over effects). Deferred costs can again be separated into direct deferred costs and indirect deferred costs. Direct deferred costs: Especially for non-feeding larvae, long-distance dispersal may be energetically costly, a price that is paid either right before (i.e., reduced effectiveness in habitat selection) and/or after colonization (i.e., reduced physiological condition) (Pechenik, 2006; Marshall et al., 2010; Burgess et al., 2012). Indirect deferred costs: dispersal may entail competitive disadvantages compared to local recruits when immigrants arrive at habitats to which they are not 
adapted (Nosil et al., 2005; Marshall et al., 2010). Marshall (2008) showed how maternally induced phenotypic adaptations to local environmental conditions can come at the cost of less competitive performance in a marine bryozoan if offspring are exposed to non-natal environments. Such phenotype-environment mismatches (sensu DeWitt et al., 1998) upon dispersal into new habitats might be common in the sea and have strong influences on patterns of connectivity by acting as a biological barrier to reproductive connectivity (reviewed in Marshall et al., 2010).

In a terrestrial context, both immediate and deferred dispersal costs are believed to scale with increasing dispersal distance and/or time (Rousset and Gandon, 2002; Stamps et al., 2005; Bonte et al., 2012). While there is evidence for selection against immigrants with longer distance dispersal from the terrestrial literature (e.g., Baker and Rao, 2004; Matter, 2006; Johnson et al., 2009), little is known of similar effects in the marine environment. Burgess et al. (2012) recently demonstrated that prolonged dispersal durations in a marine bryozoan, Bugula neritina, can result in poor recruit performance due to higher likelihoods of colonizing low-quality habitat. Such direct deferred costs may be common in marine organisms and might regularly result in non-linear mismatches between potential (dispersal) and realized (post-settlement survival) connectivity (Burgess et al., 2012).

According to terrestrial theory, dispersal costs should favor individuals that remain near the origin of the dispersal kernel, i.e., settle close to home (Nosil et al., 2005; Marshall et al., 2010; Bonte et al., 2012). The concept of dispersal costs might, however, be critically different between marine and terrestrial systems. In most terrestrial contexts, staying in or close to the natal patch reduces the negative effects of active movement through an often unsuitable matrix that is involved in inter-patch dispersal (Clobert et al., 2012). In marine environments, there is ample evidence for biophysical retention mechanisms, where larval behavior in conjunction with local- to meso-scale oceanographic phenomena may result in high rates of retention near the natal reef (Sponaugle et al., 2002; Swearer et al., 2002; Cowen et al., 2003; Paris and Cowen, 2004; Andutta et al., 2012). In the absence of such biophysical mechanisms, however, immediate and deferred dispersal costs of staying near or at the natal patch may be as great or greater than the costs involved in long-distance dispersal. First, the covered distance to disperse from patch A to patch $B$ might be as great as the distance traveled from the pelagic environment to return to the natal patch. Second, passive transport to a distant patch may be energetically more efficient than fighting ambient currents to stay near the natal patch. While at this point purely speculative, higher or equal costs of dispersal and philopatry may have profound effects on patterns of larval connectivity and would conceptually separate marine from terrestrial dispersal theory. In the described circumstances, natal homing might still be favored, however, if indirect dispersal costs outweigh immediate and direct deferred costs.

Spatially limited dispersal and retention at or near the local patch in fact seem to be more common in marine-specifically coral reef-systems than historically believed (Almany et al., 2007; Buston et al., 2011; Berumen et al., 2012; Buston and D'Aloia, 2013; but see Nanninga et al., 2014). There are indications that this recruitment back to the natal reef may indeed be driven by specific dispersal related traits or syndromes. Beldade et al. (2012) found that larger mothers of the orangefin anemonefish, A. chrysopterus, produced more natal recruits than smaller conspecifics, contributing disproportionally to local replenishment. The authors speculate that maternal effects might act upon growth-related larval traits leading to higher survival in offspring of larger mothers. Saenz-Agudelo et al. (2014) similarly found that larger mothers contributed disproportionally to local recruitment in the panda anemonefish, A. polymnus. Here, the authors speculate that this pattern may be explained by differences in fecundity among female size classes. As an alternative explanation, offspring of larger mothers may have better navigational capabilities, which they use to actively steer back to or remain near the natal reef, while lower quality individuals (i.e., produced by smaller mothers) are dispersed (see Armsworth et al., 2001). The question if and in which situations philopatry is adaptive in the sea is of vital importance for marine metapopulation theory and effective spatial conservation. Overall, the concept of marine dispersal costs and benefits clearly warrants further research efforts.

\section{Habitat fragmentation}

Habitat fragmentation has recently been gaining increasing attention as a key factor in shaping patterns of marine larval dispersal (Pinsky et al., 2012; Saenz-Agudelo et al., 2012; D'Aloia et al., 2013). As described before, terrestrial theory predicts that the spatial distance among patches in a matrix of unsuitable habitat may be an important determinant of dispersal strategies, because the cost of dispersal increases with the degree of geographic patch isolation (Bowler and Benton, 2005; Baguette and Van Dyck, 2007; Clobert et al., 2009; Baguette et al., 2012). Selection should thus favor philopatry in very isolated patches, because reaching an external patch may be too costly (Bonte et al., 2012; Baguette et al., 2013; but see Burgess et al., 2013). Indeed, the propensity to disperse away from the natal habitat was shown to decrease with increasing habitat fragmentation in various terrestrial arthropods (butterflies: Schtickzelle et al., 2006; soil mites: Bowler and Benton, 2009; waterstriders: Ahlroth et al., 2010). While as yet mostly hypothetical, the propensity of marine larvae to return to the natal patch rather than disperse might accordingly evolve as a function of increases in habitat patchiness (Baskett et al., 2007). Many sedentary species may not have the behavioral or sensory means to detect selective pressures for dispersal (e.g., kin competition) in their natal patch. In such cases, habitat fragmentation might be an important predictor of dispersal strategies. Yet, how do sedentary species detect and estimate patch isolation? Common lizards, Lacerta vivipara, for instance, were shown to carry information about their own dispersal past (Cote and Clobert, 2012). Dispersal propensities may thus be passed on to offspring via parental effects, depending on the dispersal history of the parents (see Section Parental effects). Long distance dispersal in one generation may then trigger natal homing in the next, because parents may attempt to reduce potential future dispersal costs for their offspring in isolated patches. Highly fragmented habitats would thus exhibit high rates of philopatry, while more clustered habitats might exhibit a mixture of long and short distance dispersal strategies, because recruits may arrive from both 
distant and near patches. This theory would support recent findings of higher rates of population openness (the fraction of immigrants over natal recruits) in clumped vs. isolated habitat patches in marine systems (Pinsky et al., 2012). Alternatively or additionally, probing of the water column for sensory cues by early stage larvae might trigger natal homing, if habitat cues are distant (or absent), or dispersal, if external patches appear to be closer. Such context-dependent "decisions" about dispersal would undoubtedly be more prominent in organisms with active larvae and, among those, may be more pronounced in brooding species (see Section Direct effects). If patch isolation is shaping conditiondependent dispersal strategies in marine organisms, increasing fragmentation through anthropogenic habitat loss may have farreaching consequences for patterns of population connectivity.

\section{TRANSFER}

Regardless of whether an individual displays philopatry or dispersal, most marine larval stages have an obligate pelagic period (Leis, 2006). As discussed, during this period in open water, even slight variations in larval condition, behavior, and life history traits may strongly influence dispersal trajectories (Fiksen and Jørgensen, 2011). Reciprocally, environmental conditions encountered during the pelagic phase may have profound effects on larval condition, development, and settlement success. Such matrix effects (sensu Shima and Swearer, 2009) include food availability (e.g., Meekan et al., 2003; Phillips, 2004; Donelson et al., 2009), variations in temperature (e.g., Meekan et al., 2003; Sponaugle et al., 2006; Grorud-Colvert and Sponaugle, 2011; Rankin and Sponaugle, 2011), solar radiation, wave height, wind regime, and rainfall (Bergenius et al., 2005; Macpherson and Raventos, 2005). Recent research demonstrated that the pelagic dispersal matrix has a significant influence on patterns of dispersal and settlement success (Shima et al., 2010). Using information stored in the otoliths of the common triplefin (Forsterygion lapillum), Shima and Swearer $(2009,2010)$ were able to link higher recruit quality (a composite measure of growth-related traits) to retention in local waters compared to long-distance dispersal. While their results were probably a result of strong heterogeneity in the dispersal matrix (nutrient rich near-shore vs. nutrient poor off-shore habitat), the studies strikingly establish the potential importance of different dispersal pathways for recruit condition. More recently, Shulzitski (2012) showed that residency in mesoscale eddies during the pelagic stage enhanced larval growth in four out of five reef fish species examined. Larval trajectories and local recruitment might hence not only be influenced by the interplay of hydrodynamic forcing with larval behavior (Leis, 2002), but also by individual dispersal histories and experiences in the pelagic environment.

Whether larval quality is a function of the natal environment (parental effects), dispersal history (matrix effects), or a combination thereof will have vast implications for metapopulation connectivity and our ability to accurately predict it (Shima and Swearer, 2009). Yet, few studies have so far addressed this issue and the ones that did yielded somewhat conflicting results (parental effects: Donelson et al., 2009; pelagic conditions: Shima and Swearer, 2009). Contrasting outcomes are to be expected, however, where inter- and intra-specific phenotypic variability is high and methodologies differ. Monro et al. (2010), for instance, demonstrated that selection for offspring size in bryozoans varies greatly between laboratory and field conditions and even among cohorts in the latter. Care should hence be taken when interpreting observed patterns under controlled laboratory conditions, as they may not reflect real field responses. So far the relative importance of parental effects over matrix effects on recruit quality remains largely unknown.

\section{SETTLEMENT}

In marine organisms with complex life cycles, the dispersal phase has long been known to represent a population bottleneck involving exceedingly high rates of mortality during the larval stage due to predation, starvation, or advection to unsuitable habitats (Houde, 1989; Leggett and Deblois, 1994). At the same time, even small fluctuations in larval mortality can potentially cause large variations in recruit cohorts (Caley et al., 1996; Houde, 1997). Any inter-individual variability in settlement preferences (Figure 2), sensory or locomotory abilities (Figure 3), or physiological condition (e.g., Burgess and Marshall, 2011) among late stage larvae may thus have critical effects on connectivity, because low quality individuals are less likely to successfully settle. Marshall and Keough (2003) demonstrated that the ability to delay metamorphosis varied significantly among individuals with different growth patterns in three species of marine invertebrates. While this ability to extend the larval duration increases an individual's capacity to search for suitable habitat, it may also come at a direct deferred cost after settlement (Marshall et al., 2003). Similarly, inter-individual size variation in larvae of the sea-urchin Heliocidaris erythrogramma were recently fond to confer different dispersal potential (Marshall and Steinberg, 2014). Smaller larvae settled earlier and more frequently in less preferred habitat than larger conspecifics, indicating that maternal effects on offspring size may have an important influence on settlement across life history stages. Finding, reaching, and colonizing suitable habitat after dispersal is a critical process in the life cycle, and the phenotype and condition of settlers in combination with the settlement environment may have long lasting effects on individual fitness.

\section{POST-SETTLEMENT SELECTION}

The process of metamorphosis and recruitment into the juvenile and adult population represents another critical bottleneck in marine populations, regularly involving the loss of more than half of the cohort immediately after settlement (Caley, 1998; Doherty et al., 2004; Almany and Webster, 2006). Post-settlement selection is thus a key process in recruitment regulation and may have a greater influence on population growth and dynamics than mere patch connectivity (Figueira, 2009; Carson et al., 2011; LópezDuarte et al., 2012). Predictions of population dynamics based solely on colonizer numbers may hence not effectively reflect realized connectivity, especially if incoming recruits die nonrandomly shortly after settlement (Pineda et al., 2010; Burgess and Marshall, 2011). In other words, selective post-settlement processes may decouple patterns of larval dispersal from true reproductive connectivity, the fraction of recruits that survives to reproduce (Pineda et al., 2007; Marshall and Morgan, 2011; 
Burgess et al., 2012). Early life-history mortality is often selective with respect to specific traits (Perez and Munch, 2010) and "high quality" individuals should theoretically contribute proportionately more to the population than those in poor condition (Suthers, 1998). The phenotype and physiological condition of an individual in turn may be the result of various processes during different life history stages in the natal and the dispersal environment interacting with the organism's genotype (Stamps, 2007; Figure 4). These processes may carry over across the life cycle (Burton and Metcalfe, 2014) to affect dispersal strategies in the next generation.

\section{PRACTICAL CHALLENGES}

The literature bias toward terrestrial research on dispersal polymorphisms is not surprising considering the relative difficulty of sample collection, direct observation, and tracking individuals in marine systems. Studies pertaining to the interaction of larval histories, phenotypic traits, and selective mortality in the sea are facing some critical methodological challenges, particularly regarding non-sessile organisms (Johnson et al., 2012). For one, high rates of mobility and natural mortality preclude continuous measures of traits in specific individuals over time. Moreover, the identification of dispersal histories as well as most traits of interest requires the lethal sampling of individuals. Many studies hence employ a cross-sectional approach during which specific traits are measured in different individuals before and after a selective event. Distributions of traits are then compared between preselection (e.g., larvae) and post-selection samples (e.g., recruits) (Johnson et al., 2012). Many of these studies reconstruct early life history traits in post-settlement individuals via incremental depositions in hard structures, such as otoliths in fish (e.g., Hamilton et al., 2008), or shells in invertebrates (e.g., Carson et al., 2011). Analysis of isotopic composition of these increments may assist in the identification of individual larval sources and/or dispersal environments (Shima and Swearer, 2009; but see Berumen et al., 2010). While these kinds of analyses have proven to be invaluable for the reconstruction of larval histories in the light of selective survival, we argue that the power of such approaches could be raised significantly if combined with empirical techniques (e.g., larval tagging, parentage analysis).

On smaller spatial scales, genetic parentage analysis has proven to be a useful tool in the study of larval dispersal; however, we argue that this approach has not yet been employed to its full potential. Parentage analysis has so far mostly been used in a purely descriptive way to measure self-recruitment and to a lesser degree connectivity among adjacent reefs (e.g., Planes et al., 2009; Saenz-Agudelo et al., 2011; Harrison et al., 2012; SaenzAgudelo et al., 2012; Almany et al., 2013). Beldade et al. (2012) point toward a more hypothesis-driven way of using parentage by relating levels of self-recruitment to maternal size. There is clearly high potential to employ kinship analysis in a more explicit background. The power to identify parent-offspring pairs and distinguish between natal and external recruits in situ could be used to assess a whole range of maternal effects, dispersal costs, or the influence of habitat fragmentation on dispersal strategies. If recruits could be monitored over time (i.e., sampled nonlethally), such studies could be extended to include carry-over effects on post-settlement performance in the field. The apparent evolutionary and ecological significance of individual variability in larval dispersal clearly warrants further research efforts and we will probably witness this field developing notably over the next few years.

\section{CONCLUSIONS}

Condition- and context-dependent dispersal, the concept of inter-individual variability in the costs-benefit ratios of dispersal, has recently received increasing attention in the terrestrial literature. It remains uncertain to what extent these concepts can be applied to marine larval dispersal where neutral processes are generally more influential. There is clear evidence of inter-individual variability among larvae of marine organisms in traits related to dispersal as well as in larval quality. Yet, little research has focused explicitly on the quantification of this variation and there is an urgent need to conceptually link phenotypic heterogeneity to emergent population-wide dispersal patterns. The interaction of variable phenotypes with environmental conditions and vice versa may not only influence an individual's ability to disperse, but also its propensity toward dispersal. Larvae with active navigational control over their dispersal trajectories may thus exhibit specific dispersal strategies depending on the external (e.g., habitat heterogeneity and fragmentation) and internal (e.g., physiological condition) context.

Different stages in the life cycle of many marine organisms are not independent and carry-over effects of parental dispersal history, the natal origin, as well as the dispersal matrix may affect individual phenotype and quality. Internal and external variation in any life stage can thus affect dispersal and propagate beyond settlement to affect realized dispersal. It is increasingly becoming apparent that we need to look beyond individual life stages and single generations when studying larval dispersal.

Recent research provides compelling evidence for the importance of dispersal costs and individual quality on patterns of dispersal and post-settlement selection in marine organisms. Yet, the concept of dispersal costs may differ between terrestrial and marine systems. The correlation of trait variation with dispersal patterns may thus not be straightforward. Better swimming abilities in fish larvae, for instance, may indicate an adaptation to long distance dispersal, or may be used to stay near or return to the natal patch. We advocate future research into the implications of phenotype-dependent dispersal in marine systems ecology. The adaptation of terrestrial theory to marine systems may entail a conceptual advancement for the study of marine metapopulation dynamics.

\section{AUTHOR CONTRIBUTIONS}

Gerrit B. Nanninga conceived the content and wrote the manuscript. Michael L. Berumen critically revised and approved the manuscript.

\section{ACKNOWLEDGMENTS}

The authors would like to thank Andrea Manica, Chris Fulton, Stephen Swearer, and four anonymous reviewers for helpful comments on previous versions of the manuscript. We thank Rebecca Fisher for the contribution of data on larval swimming speeds 
and Pablo Saenz-Agudelo, Geoff Jones, Serge Planes, and Simon Thorrold for data on parentage assignments at Kimbe Island. This project was supported by KAUST Red Sea Research Center funding (Michael L. Berumen) and a Competitive Research Grant (URF/1/1700-01-01) (Michael L. Berumen and Gerrit B. Nanninga).

\section{REFERENCES}

Abdul Wahab, M., de Nys, R., and Whalan, S. (2011). Larval behaviour and settlement cues of a brooding coral reef sponge. Coral Reefs 30, 451-460. doi: 10.1007/s00338-011-0727-5

Ahlroth, P., Alatalo, R. V., and Suhonen, J. (2010). Reduced dispersal propensity in the wingless waterstrider Aquarius najas in a highly fragmented landscape. Oecologia 162, 323-330. doi: 10.1007/s00442-009-1457-z

Allen, R. M., and Marshall, D. J. (2010). The larval legacy: cascading effects of recruit phenotype on post-recruitment interactions. Oikos 119, 1977-1983. doi: 10.1111/j.1600-0706.2010.18682.x

Almany, G. R., Berumen, M. L., Thorrold, S. R., Planes, S., and Jones, G. P. (2007). Local replenishment of coral reef fish populations in a marine reserve. Science 316, 742-744. doi: 10.1126/science.1140597

Almany, G. R., Hamilton, R. J., Bode, M., Matawai, M., Potuku, T., SaenzAgudelo, P., et al. (2013). Dispersal of grouper larvae drives local resource sharing in a coral reef fishery. Curr. Biol. 23, 626-630. doi: 10.1016/j.cub.2013. 03.006

Almany, G. R., and Webster, M. S. (2006). The predation gauntlet: early postsettlement mortality in reef fishes. Coral Reefs 25, 19-22. doi: 10.1007/s00338005-0044-y

Anderson, J. T. (1988). A review of size dependent survival during pre-recruit stages of fishes in relation to recruitment. J. Northwest Atl. Fish. Sci. 8, 55-66.

Andutta, F. P., Kingsford, M. J., and Wolanski, E. (2012). "Sticky water" enables the retention of larvae in a reef mosaic. Estuar. Coast. Shelf Sci. 101, 54-63. doi: 10.1016/j.ecss.2012.02.013

Armsworth, P. R., James, M. K., and Bode, L. (2001). When to press on or turn back: dispersal strategies for reef fish larvae. Am. Nat. 157, 434-450. doi: $10.1086 / 319322$

Arvedlund, M., McCormick, M. I., Fautin, D. G., and Bildsøe, M. (1999). Host recognition and possible imprinting in the anemonefish Amphiprion melanopus (Pisces: Pomacentridae). Mar. Ecol. Prog. Ser. 188, 207-218. doi: 10.3354/meps 188207

Arvedlund, M., and Nielsen, L. E. (1996). Do the anemonefish Amphiprion ocellaris (Pisces: Pomacentridae) imprint themselves to their host sea anemone Heteractis magnifica (Anthozoa: Actinidae)? Ethology 102, 197-211. doi: 10.1111/j.1439-0310.1996.tb01118.x

Atema, J., Kingsford, M. J., and Gerlach, G. (2002). Larval reef fish could use odour for detection, retention and orientation to reefs. Mar. Ecol. Prog. Ser. 241, 151-160. doi: 10.3354/meps241151

Baguette, M., Blanchet, S., Legrand, D., Stevens, V. M., and Turlure, C. (2013). Individual dispersal, landscape connectivity and ecological networks. Biol. Rev. Camb. Philos. Soc. 88, 310-326. doi: 10.1111/brv.12000

Baguette, M., Legrand, D., Fréville, H., Van Dyck, H., and Ducatez, S. (2012). "Evolutionary ecology of dispersal in fragmented landscape," in Dispersal Ecology and Evolution, eds J. Clobert, M. Baguette, T. G. Benton, and J. M. Bullock (Oxford: Oxford University Press), 381-391.

Baguette, M., and Van Dyck, H. (2007). Landscape connectivity and animal behavior: functional grain as a key determinant for dispersal. Landsc. Ecol. 22, 1117-1129. doi: 10.1007/s10980-007-9108-4

Baker, M. B., and Rao, S. (2004). Incremental costs and benefits shape natal dispersal: theory and example with Hemilepistus reaumuri. Ecology 85, 1039-1051. doi: 10.1890/02-0507

Baskett, M. L., Weitz, J. S., and Levin, S. A. (2007). The evolution of dispersal in reserve networks. Am. Nat. 170, 59-78. doi: 10.1086/518184

Beldade, R., Holbrook, S. J., Schmitt, R. J., Planes, S., Malone, D., and Bernardi, G. (2012). Larger female fish contribute disproportionately more to selfreplenishment. Proc. Biol. Sci. 279, 2116-2121. doi: 10.1098/rspb.2011.2433

Benard, M. F., and McCauley, S. J. (2008). Integrating across life-history stages: consequences of natal habitat effects on dispersal. Am. Nat. 171, 553-567. doi: $10.1086 / 587072$
Benton, T. G., Plaistow, S. J., and Coulson, T. N. (2006). Complex population dynamics and complex causation: devils, details and demography. Proc. R. Soc. B Biol. Sci. 273, 1173-1181. doi: 10.1098/rspb.2006.3495

Bergenius, M. A. J., McCormick, M. I., Meekan, M. G., and Robertson, D. R. (2005). Environmental influences on larval duration, growth and magnitude of settlement of a coral reef fish. Mar. Biol. 147, 291-300. doi: 10.1007/s00227005-1575-Z

Bergenius, M. A., Meekan, M. G., Robertson, R. D., and McCormick, M. I. (2002). Larval growth predicts the recruitment success of a coral reef fish. Oecologia 131, 521-525. doi: 10.1007/s00442-002-0918-4

Berkeley, S. A., Chapman, C., and Sogard, S. M. (2004). Maternal age as a determinant of larval growth and survival in a marine fish, Sebastes melanops. Ecology 85, 1258-1264. doi: 10.1890/03-0706

Bernard, M. F., and McCauley, S. J. (2001). Integrating across life-history stages: consequences of natal habitat effects on dispersal. Am. Nat. 171, 553-567. doi: $10.1086 / 587072$

Berumen, M. L., Almany, G. R., Planes, S., Jones, G. P., Saenz-Agudelo, P., and Thorrold, S. R. (2012). Persistence of self-recruitment and patterns of larval connectivity in a marine protected area network. Ecol. Evol. 2, 444-452. doi: 10.1002/ece3.208

Berumen, M. L., Walsh, H. J., Raventos, N., Planes, S., Jones, G. P., Starczak, V., et al. (2010). Otolith geochemistry does not reflect dispersal history of clownfish larvae. Coral Reefs 29, 883-891. doi: 10.1007/s00338-010-0652-z

Binning, S. A., Roche, D. G., and Fulton, C. J. (2014). Localised intraspecific variation in the swimming phenotype of a coral reef fish across different wave exposures. Oecologia 174, 623-630. doi: 10.1007/s00442-013-2794-5

Bitume, E. V., Bonte, D., Magalhães, S., San Martin, G., Van Dongen, S., Bach, F., et al. (2011). Heritability and artificial selection on ambulatory dispersal distance in Tetranychus urticae: effects of density and maternal effects. PLoS ONE 6:e26927. doi: 10.1371/journal.pone.0026927

Bobe, J., and Labbé, C. (2010). Egg and sperm quality in fish. Gen. Comp. Endocrinol. 165, 535-548. doi: 10.1016/j.ygcen.2009.02.011

Bolnick, D. I., Amarasekare, P., Araújo, M. S., Bürger, R., Levine, J. M., Novak, M., et al. (2011). Why intraspecific trait variation matters in community ecology. Trends Ecol. Evol. 26, 183-192. doi: 10.1016/j.tree.2011.01.009

Bonte, D., Hovestadt, T., and Poethke, H.-J. (2010). Evolution of dispersal polymorphism and local adaptation of dispersal distance in spatially structured landscapes. Oikos 119, 560-566. doi: 10.1111/j.1600-0706.2009.1 7943.x

Bonte, D., Van Dyck, H., Bullock, J. M., Coulon, A., Delgado, M., Gibbs, M., et al. (2012). Costs of dispersal. Biol. Rev. Camb. Philos. Soc. 87, 290-312. doi: 10.1111/j.1469-185X.2011.00201.x

Bowler, D. E., and Benton, T. G. (2005). Causes and consequences of animal dispersal strategies: relating individual behaviour to spatial dynamics. Biol. Rev. Camb. Philos. Soc. 80, 205-225. doi: 10.1017/S1464793104006645

Bowler, D. E., and Benton, T. G. (2009). Impact of dispersal on population growth: the role of inter-patch distance. Oikos 118, 403-412. doi: 10.1111/j.16000706.2008.17049.x

Bowler, D. E., and Benton, T. G. (2011). Testing the interaction between environmental variation and dispersal strategy on population dynamics using a soil mite experimental system. Oecologia 166, 111-119. doi: 10.1007/s00442-0101820-0

Brooks, S., Tyler, C. R., and Sumpter, J. P. (1997). Egg quality in fish: what makes a good egg? Rev. Fish Biol. Fish. 7, 387-416. doi: 10.1023/A:1018400130692

Burgess, S. C., Bode, M., and Marshall, D. J. (2013). Costs of dispersal alter optimal offspring size in patchy habitats: combining theory and data for a marine invertebrate. Funct. Ecol. 27, 757-765. doi: 10.1111/1365-2435. 12080

Burgess, S. C., and Marshall, D. J. (2011). Are numbers enough? colonizer phenotype and abundance interact to affect population dynamics. J. Anim. Ecol. 80, 681-687. doi: 10.1111/j.1365-2656.2010.01802.x

Burgess, S. C., Treml, E. A, and Marshall, D. J. (2012). How do dispersal costs and habitat selection influence realized population connectivity? Ecology 93, 1378-1387. doi: 10.1890/11-1656.1

Burton, T., and Metcalfe, N. B. (2014). Can environmental conditions experienced in early life influence future generations? Proc. R. Soc. B Biol. Sci. 281, 20140311. doi: $10.1098 /$ rspb.2014.0311

Buston, P. M., and D'Aloia, C. C. (2013). Marine ecology: reaping the benefits of local dispersal. Curr. Biol. 23, R351-R353. doi: 10.1016/j.cub.2013.03.056 
Buston, P. M., Jones, G. P., Planes, S., and Thorrold, S. R. (2011). Probability of successful larval dispersal declines fivefold over $1 \mathrm{~km}$ in a coral reef fish. Proc. Biol. Sci. 279, 1883-1888. doi: 10.1098/rspb.2011.2041

Caley, M. J. (1998). Age-specific mortality rates in reef fishes: evidence and implications. Aust. J. Ecol. 23, 241-245. doi: 10.1111/j.1442-9993.1998.tb00726.x

Caley, M. J., Carr, M. H., Hixon, M. A., Hughes, T. P., Jones, G. P., and Menge, B. A. (1996). Recruitment and the local dynamics of open marine populations. Annu. Rev. Ecol. Syst. 27, 477-500. doi: 10.1146/annurev.ecolsys.27.1.477

Carr, M. H., Neigel, J. E., Estes, J. A., Andelman, S., Warner, R. R., and Largier, J. L. (2003). Comparing marine and terrestrial ecosystems: implications for the design of coastal marine reserves. Ecol. Appl. 13, 90-107. doi: 10.1890/10510761(2003)013[0090:CMATEI]2.0.CO;2

Carson, H. S., Cook, G. S., López-Duarte, P. C., and Levin, L. A. (2011). Evaluating the importance of demographic connectivity in a marine metapopulation. Ecology 92, 1972-1984. doi: 10.1890/11-0488.1

Chia, F. S., Gibson, G., and Qian, P. Y. (1996). Poecilogony as a reproductive strategy of marine invertebrates. Oceanol. Acta 19, 203-208.

Clobert, J., Baguette, M., Benton, T. G., and Bullock, J. M. (2012). Dispersal Ecology and Evolution. Oxford: Oxford University Press.

Clobert, J., Danchin, E., Dhondt, A., and Nichols, J. (2001). Dispersal. Oxford: Oxford University Press.

Clobert, J., Le Galliard, J.-F., Cote, J., Meylan, S., and Massot, M. (2009). Informed dispersal, heterogeneity in animal dispersal syndromes and the dynamics of spatially structured populations. Ecol. Lett. 12, 197-209. doi: 10.1111/j.14610248.2008.01267.x

Coleman, K., and Wilson, D. S. (1998). Shyness and boldness in pumpkinseed sunfish: individual differences are context-specific. Anim. Behav. 56, 927-936. doi: 10.1006/anbe.1998.0852

Cote, J., and Clobert, J. (2012). "Dispersal syndromes in the common lizard: personality traits, information use, and context-dependent dispersal," in Dispersal Ecology and Evolution, eds J. Clobert, M. Baguette, T. G. Benton, and J. M. Bullock (Oxford: Oxford University Press), 152-160.

Cote, J., Clobert, J., Brodin, T., Fogarty, S., and Sih, A. (2010). Personalitydependent dispersal: characterization, ontogeny and consequences for spatially structured populations. Philos. Trans. R. Soc. B Biol. Sci. 365, 4065-4076. doi: 10.1098/rstb.2010.0176

Cowen, R. K., Paris, C. B., Olson, D. B., and Fortuna, J. L. (2003). The role of long distance dispersal versus local retention in replenishing marine populations. Gulf Caribb. Res. 14, 129-138.

Cowen, R. K., Paris, C. B., and Srinivasan, A. (2006). Scaling of connectivity in marine populations. Science 311, 522-527. doi: 10.1126/science.1122039

Cowen, R. K., and Sponaugle, S. (2009). Larval dispersal and marine population connectivity. Ann. Rev. Mar. Sci. 1, 443-466. doi: 10.1146/annurev.marine.010908.163757

Crean, A. J., Dwyer, J. M., and Marshall, D. J. (2013). Adaptive paternal effects? experimental evidence that the paternal environment affects offspring performance. Ecology 94, 2575-2582. doi: 10.1890/13-0184.1

Crean, A. J., and Marshall, D. J. (2009). Coping with environmental uncertainty: dynamic bet hedging as a maternal effect. Philos. Trans. R. Soc. B Biol. Sci. 364, 1087-1096. doi: 10.1098/rstb.2008.0237

D’Alessandro, E. K., Sponaugle, S., and Cowen, R. K. (2013). Selective mortality during the larval and juvenile stages of snappers (Lutjanidae) and great barracuda Sphyraena barracuda. Mar. Ecol. Prog. Ser. 474, 227-242. doi: $10.3354 /$ meps 10114

D’Aloia, C. C., Bogdanowicz, S. M., Majoris, J. E., Harrison, R. G., and Buston, P. M. (2013). Self-recruitment in a Caribbean reef fish: a method for approximating dispersal kernels accounting for seascape. Mol. Ecol. 22, 2563-2572. doi: $10.1111 / \mathrm{mec} .12274$

Davis, J. M., and Stamps, J. A. (2004). The effect of natal experience on habitat preferences. Trends Ecol. Evol. 19, 411-416. doi: 10.1016/j.tree.2004.04.006

Dawideit, B. A., Phillimore, A. B., Laube, I., Leisler, B., and Böhning-Gaese, K. (2009). Ecomorphological predictors of natal dispersal distances in birds. J. Anim. Ecol. 78, 388-395. doi: 10.1111/j.1365-2656.2008.01504.x

Dawson, M. N., and Hamner, W. M. (2008). A biophysical perspective on dispersal and the geography of evolution in marine and terrestrial systems. J. R. Soc. Interface 5, 135-150. doi: 10.1098/rsif.2007.1089

DeWitt, T. J., Sih, A., and Wilson, D. S. (1998). Costs and limits of phenotypic plasticity. Trends Ecol. Evol. 13, 77-81. doi: 10.1016/S0169-5347(97)0 1274-3
Dias, G. M., and Marshall, D. J. (2010). Does the relationship between offspring size and performance change across the life-history? Oikos 119, 154-162. doi: 10.1111/j.1600-0706.2009.17725.x

Dingle, H. (1996). Migration: the Biology of Life on the Move. New York, NY: Oxford University Press.

Dixson, D. L. (2012). Predation risk assessment by larval reef fishes during settlement-site selection. Coral reefs 31, 255-261. doi: 10.1007/s00338-0110842-3

Dixson, D. L., Jones, G. P., Munday, P. L., Planes, S., Pratchett, M. S., Srinivasan, M., et al. (2008). Coral reef fish smell leaves to find island homes. Proc. R. Soc. B 275, 2831-2839. doi: 10.1098/rspb.2008.0876

Dixson, D. L., Jones, G. P., Munday, P. L., Planes, S., Pratchett, M. S., and Thorrold, S. R. (2014). Experimental evaluation of imprinting and the role innate preference plays in habitat selection in a coral reef fish. Oecologia 174, 99-107. doi: 10.1007/s00442-013-2755-z

Dixson, D. L., Jones, G. P., Munday, P. L., Pratchett, M. S., Srinivasan, M., Planes, S., et al. (2011). Terrestrial chemical cues help coral reef fish larvae locate settlement habitat surrounding islands. Ecol. Evol. 1, 586-595. doi: 10.1002/ece3.53

Doherty, P. J., Dufour, V., Galzin, R., Hixon, M. A., Meekan, M. G., and Planes, S. (2004). High mortality during settlement is a population bottleneck for a tropical surgeonfish. Ecology 85, 2422-2428. doi: 10.1890/04-0366

Donelson, J. M., Munday, P. L., and McCormick, M. I. (2009). Parental effects on offspring life histories: when are they important? Biol. Lett. 5, 262-265. doi: 10.1098/rsbl.2008.0642

Donelson, J. M., Munday, P. L., McCormick, M. I., and Pitcher, C. R. (2012). Rapid transgenerational acclimation of a tropical reef fish to climate change. Nat. Clim. Chang. 2, 30-32. doi: 10.1038/nclimate1323

Duckworth, R. A. (2008). Adaptive dispersal strategies and the dynamics of a range expansion. Am. Nat. 172, S4-S17. doi: 10.1086/588289

Dupont, S., Dorey, N., Stumpp, M., Melzner, F., and Thorndyke, M. (2013). Longterm and trans-life-cycle effects of exposure to ocean acidification in the green sea urchin Strongylocentrotus droebachiensis. Mar. Biol. 160, 1835-1843. doi: 10.1007/s00227-012-1921-x

Figueira, W. F. (2009). Connectivity or demography: defining sources and sinks in coral reef fish metapopulations. Ecol. Model. 220, 1126-1137. doi: 10.1016/j.ecolmodel.2009.01.021

Fiksen, Ø., and Jørgensen, C. (2011). Model of optimal behaviour in fish larvae predicts that food availability determines survival, but not growth. Mar. Ecol. Prog. Ser. 432, 207-219. doi: 10.3354/meps09148

Fiksen, Ø., Jørgensen, C., Kristiansen, T., Vikebø, F., and Huse, G. (2007). Linking behavioural ecology and oceanography: larval behaviour determines growth, mortality and dispersal. Mar. Ecol. Prog. Ser. 347, 195-205. doi: $10.3354 /$ meps06978

Fisher, R. (2005). Swimming speeds of larval coral reef fishes: impacts on self-recruitment and dispersal. Mar. Ecol. Prog. Ser. 285, 223-232. doi: $10.3354 /$ meps 285223

Fisher, R., and Bellwood, D. (2002). The influence of swimming speed on sustained swimming performance of late-stage reef fish larvae. Mar. Biol. 140, 801-807. doi: 10.1007/s00227-001-0758-5

Fisher, R., Bellwood, D., and Job, S. (2000). Development of swimming abilities in reef fish larvae. Mar. Ecol. Prog. Ser. 202, 163-173. doi: 10.3354/meps202163

Fisher, R., and Bellwood, D. R. (2003). Undisturbed swimming behaviour and nocturnal activity of coral reef fish larvae. Mar. Ecol. Prog. Ser. 263, 177-188. doi: $10.3354 /$ meps 263177

Fisher, R., Leis, J. M., Clark, D. L., and Wilson, S. K. (2005). Critical swimming speeds of late-stage coral reef fish larvae: variation within species, among species and between locations. Mar. Biol. 147, 1201-1212. doi: 10.1007/s00227-0050001-x

Fogarthy, M. J., and Botsford, L. W. (2007). Population connectivity and spatial management of marine fisheries. Oceanography 20, 112-123. doi: 10.5670/oceanog.2007.34

Fox, C. W., and Czesak, M. E. (2000). Evolutionary ecology of progeny size in arthropods. Annu. Rev. Entomol. 45, 341-369. doi: 10.1146/annurev.ento. 45.1.341

Fuiman, L., a, Meekan, M. G., and McCormick, M. I. (2010). Maladaptive behavior reinforces a recruitment bottleneck in newly settled fishes. Oecologia 164, 99-108. doi: 10.1007/s00442-010-1712-3

Fulton, C. J., Binning, S. A., Wainwright, P. C., and Bellwood, D. R. (2013). Wave-induced abiotic stress shapes phenotypic diversity in a coral reef fish 
across a geographical cline. Coral reefs 32, 685-689. doi: 10.1007/s00338-0131039-8

Gagliano, M., and McCormick, M. I. (2007). Maternal condition influences phenotypic selection on offspring. J. Anim. Ecol. 76, 174-182. doi: 10.1111/j.13652656.2006.01187.x

Gagliano, M., McCormick, M. I., and Meekan, M. G. (2007). Survival against the odds: ontogenetic changes in selective pressure mediate growth-mortality trade-offs in a marine fish. Proc. R. Soc. B Biol. Sci. 274, 1575-1582. doi: 10.1098/rspb.2007.0242

Gaines, S. D., Lester, S. E., Grorud-Colvert, K., Costello, C., and Pollnac, R. (2010). Evolving science of marine reserves: new developments and emerging research frontiers. Proc. Natl. Acad. Sci. U.S.A. 107, 18251-18255. doi: 10.1073/pnas.1002098107

Galloway, L. F. (2005). Maternal effects provide phenotypic adaptation to local environmental conditions. New Phytol. 166, 93-100. doi: 10.1111/j.14698137.2004.01314.x

Galloway, L. F., and Etterson, J. R. (2007). Transgenerational plasticity is adaptive in the wild. Science 318, 1134-1136. doi: 10.1126/science.1148766

George, S. B. (1994). Population differences in maternal size and offspring quality for Leptasterias epichlora (Brandt) (Echinodermata: Asteroidea). J. Exp. Mar. Bio. Ecol. 175, 121-131. doi: 10.1016/0022-0981(94)90179-1

Gerlach, G., Atema, J., Kingsford, M. J., Black, K. P., and Miller-Sims, V. (2007). Smelling home can prevent dispersal of reef fish larvae. Proc. Natl. Acad. Sci. U.S.A. 104, 858-863. doi: 10.1073/pnas.0606777104

Gibbs, M., Saastamoinen, M., Coulon, A., and Stevens, V. M. (2010). Organisms on the move: ecology and evolution of dispersal. Biol. Lett. 6, 146-148. doi: 10.1098/rsbl.2009.0820

Gobler, C. J., and Talmage, S. C. (2013). Short-and long-term consequences of larval stage exposure to constantly and ephemerally elevated carbon dioxide for marine bivalve populations. Biogeosciences 10, 2241-2253. doi: 10.5194/bg-102241-2013

Green, B. S. (2008). Maternal effects in fish populations. Adv. Mar. Biol. 54, 1-105. doi: 10.1016/S0065-2881(08)00001-1

Green, B. S., and McCormick, M. I. (2005). Maternal and paternal effects determine size, growth and performance in larvae of a tropical reef fish. Mar. Ecol. Progr. Ser. 289, 263-272. doi: 10.3354/meps 289263

Grorud-Colvert, K., and Sponaugle, S. (2011). Variability in water temperature affects trait-mediated survival of a newly settled coral reef fish. Oecologia 165, 675-686. doi: 10.1007/s00442-010-1748-4

Hamilton, S. L. (2008). Larval history influences post-metamorphic condition in a coral-reef fish. Oecologia 158, 449-461. doi: 10.1007/s00442-008-1153-4

Hamilton, S. L., Regetz, J., and Warner, R. R. (2008). Postsettlement survival linked to larval life in a marine fish. Proc. Natl. Acad. Sci. U.S.A. 105, 1561-1566. doi: 10.1073/pnas.0707676105

Hanski, I. (1998). Metapopulation dynamics. Nature 396, 41-49. doi: $10.1038 / 23876$

Harrison, H. B., Williamson, D. H., Evans, R. D., Almany, G. R., Thorrold, S. R., Russ, G. R., et al. (2012). Larval export from marine reserves and the recruitment benefit for fish and fisheries. Curr. Biol. 22, 1023-1028. doi: 10.1016/j.cub.2012.04.008

Haugen, T. O., and Vøllestad, L. A. (2000). Population differences in early life-history traits in grayling. J. Evol. Biol. 13, 897-905. doi: 10.1046/j.14209101.2000.00242.x

Herman, J. J., and Sultan, S. E. (2011). Adaptive transgenerational plasticity in plants: case studies, mechanisms, and implications for natural populations. Front. Plant Sci. 2:102. doi: 10.3389/fpls.2011.00102

Hettinger, A., Sanford, E., Hill, T. M., Lenz, E. A., Russell, A. D., and Gaylord, B. (2013). Larval carry-over effects from ocean acidification persist in the natural environment. Glob. Chang. Biol. 19, 3317-3326. doi: 10.1111/gcb. 12307

Hettinger, A., Sanford, E., Hill, T. M., Russell, A. D., Sato, K. N. S., Hoey, J., et al. (2012). Persistent carry-over effects of planktonic exposure to ocean acidification in the Olympia oyster. Ecology 93, 2758-2768. doi: 10.1890/120567.1

Hixon, M. A. (2011). 60 years of coral reef fish ecology: past, present, future. Bull. Mar. Sci. 87, 727-765. doi: 10.5343/bms.2010.1055

Hoagland, K. E., and Robertson, R. (1988). An assessment of poecilogony in marine invertebrates: phenomenon or fantasy? Biol. Bull. 174, 109-125. doi: $10.2307 / 1541778$
Hoey, A. S., and McCormick, M. I. (2004). Selective predation for low body condition at the larval-juvenile transition of a coral reef fish. Oecologia 139, 23-29. doi: 10.1007/s00442-004-1489-3

Hogan, J. D., McIntyre, P. B., Blum, M. J., Gilliam, J. F., and Bickford, N. (2014). Consequences of alternative dispersal strategies in a putatively amphidromous fish. Ecology 95, 2397-2408. doi: 10.1890/13-0576.1

Houde, E. D. (1989). Comparative growth, mortality, and energetics of marine fish larvae: temperature and implied latitudinal effects. Fish. Bull. 87, 471-495.

Houde, E. D. (1997). Patterns and trends in larval-stage growth and mortality of teleost fish. J. Fish Biol. 51, 52-83. doi: 10.1111/j.1095-8649.1997.tb 06093.x

Huey, J. A., Crook, D. A., Macdonald, J. I., Schmidt, D. J., Marshall, J. C., Balcombe, S. R., et al. (2014). Is variable connectivity among populations of a continental gobiid fish driven by local adaptation or passive dispersal? Freshw. Biol. 59, 1672-1686. doi: 10.1111/fwb. 12373

Immelmann, K. (1975). Ecological significance of imprinting and early learning. Annu. Rev. Ecol. Syst. 6, 15-37. doi: 10.1146/annurev.es.06.110175.000311

Jeffs, A. G., Montgomery, J. C., and Tindle, C. T. (2005). How do spiny lobster post-larvae find the coast? New Zeal. J. Mar. Freshw. Res. 39, 605-617. doi: 10.1080/00288330.2005.9517339

Jeffs, A., Tolimieri, N., and Montgomery, J. C. (2003). Crabs on cue for the coast: the use of underwater sound for orientation by pelagic crab stages. Mar. Freshw. Res. 54, 841-845. doi: 10.1071/MF03007

Johnson, C. A., Fryxell, J. M., Thompson, I. D., and Baker, J. A. (2009). Mortality risk increases with natal dispersal distance in American martens. Proc. R. Soc. B Biol. Sci. 276, 3361-3367. doi: 10.1098/rspb.2008.1958

Johnson, D., Grorud-Colvert, K., Rankin, T., and Sponaugle, S. (2012). Measuring selective mortality from otoliths and similar structures: a practical guide for describing multivariate selection from cross-sectional data. Mar. Ecol. Prog. Ser. 471, 151-163. doi: 10.3354/meps10028

Johnson, D. W. (2008). Combined effects of condition and density on postsettlement survival and growth of a marine fish. Oecologia 155, 43-52. doi: 10.1007/s00442-007-0882-0

Johnson, D. W., and Hixon, M. A. (2010). Ontogenetic and spatial variation in size-selective mortality of a marine fish. J. Evol. Biol. 23, 724-737. doi: 10.1111/j.1420-9101.2010.01938.x

Jones, G. P., Almany, G. R., Russ, G. R., Sale, P. F., Steneck, R. S., Oppen, M. J. H., et al. (2009). Larval retention and connectivity among populations of corals and reef fishes: history, advances and challenges. Coral Reefs 28, 307-325. doi: 10.1007/s00338-009-0469-9

Jopp, F., and Reuter, H. (2005). Dispersal of carabid beetles-emergence of distribution patterns. Ecol. Modell. 186, 389-405. doi: 10.1016/j.ecolmodel.2005. 02.009

Jørgensen, C., Opdal, A. F., and Fiksen, Ø. (2013). Can behavioural ecology unite hypotheses for fish recruitment? ICES J. Mar. Sci. J. du Cons. 71, 909-917. doi: 10.1093/icesjms/fst083

Kawecki, T. J., and Ebert, D. (2004). Conceptual issues in local adaptation. Ecol. Lett. 7, 1225-1241. doi: 10.1111/j.1461-0248.2004.00684.x

Kesselring, H., Wheatley, R., and Marshall, D. (2012). Initial offspring size mediates trade-off between fecundity and longevity in the field. Mar. Ecol. Prog. Ser. 465, 129-136. doi: 10.3354/meps09865

Kingsford, M. J., Leis, J. M., Shanks, A., Lindeman, K. C., Morgan, S. G., and Pineda, J. (2002). Sensory environments, larval abilities and local self-recruitment. Bull. Mar. Sci. 70, 309-340.

Kinlan, B. P., and Gaines, S. D. (2003). Propagule dispersal in marine and terrestrial environments: a community perspective. Ecology 84, 2007-2020. doi: 10.1890/01-0622

Knott, K. E., and McHugh, D. (2012). Introduction to symposium: poecilogonyA window on larval evolutionary transitions in marine invertebrates. Integr. Comp. Biol. 52, 120-127. doi: 10.1093/icb/ics037

Kritzer, J. P., and Sale, P. F. (2004). Metapopulation ecology in the sea: from Levins' model to marine ecology and fisheries science. Fish Fish. 5, 131-140. doi: 10.1111/j.1467-2979.2004.00131.x

Krug, P. J. (2007). Poecilogony and larval ecology in the gastropod genus Alderia. Am. Malacol. Bull. 23, 99-111. doi: 10.4003/0740-2783-23.1.99

Krug, P. J., Gordon, D., and Romero, M. R. (2012). Seasonal polyphenism in larval type: rearing environment influences the development mode expressed by adults in the sea slug Alderia willowi. Integr. Comp. Biol. 52, 161-172. doi: $10.1093 / \mathrm{icb} / \mathrm{ics} 059$ 
Lecchini, D. (2011). Visual and chemical cues in habitat selection of sepioid larvae. C. R. Biol. 334, 911-915. doi: 10.1016/j.crvi.2011.08.003

Lecchini, D., Osenberg, C. W., Shima, J. S., St Mary, C. M., and Galzin, R. (2007). Ontogenetic changes in habitat selection during settlement in a coral reef fish: ecological determinants and sensory mechanisms. Coral Reefs 26, 423-432. doi: 10.1007/s00338-007-0212-3

Lecchini, D., Planes, S., and Galzin, R. (2005a). Experimental assessment of sensory modalities of coral-reef fish larvae in the recognition of their settlement habitat. Behav. Ecol. Sociobiol. 58, 18-26. doi: 10.1007/s00265-004-0905-3

Lecchini, D., Shima, J., Banaigs, B., and Galzin, R. (2005b). Larval sensory abilities and mechanisms of habitat selection of a coral reef fish during settlement. Oecologia 143, 326-334. doi: 10.1007/s00442-004-1805-y

Leggett, W. C., and Deblois, E. (1994). Recruitment in marine fishes: is it regulated by starvation and predation in the egg and larval stages? Netherlands J. Sea Res. 32, 119-134. doi: 10.1016/0077-7579(94)90036-1

Leis, J. M. (2002). Pacific coral-reef fishes: the implications of behaviour and ecology of larvae for biodiversity and conservation, and a reassessment of the open population paradigm. Environ. Biol. Fishes 65, 199-208. doi: 10.1023/A:1020096720543

Leis, J. M. (2006). Are larvae of demersal fishes plankton or nekton? Adv. Mar. Biol. 51, 57-141. doi: 10.1016/S0065-2881(06)51002-8

Leis, J. M. (2007). Behaviour as input for modelling dispersal of fish larvae: behaviour, biogeography, hydrodynamics, ontogeny, physiology and phylogeny meet hydrography. Mar. Ecol. Prog. Ser. 347, 185-193. doi: 10.3354/meps 06977

Levin, L. A., and Bridges, T. S. (1995). "Pattern and diversity in reproduction and development," in Ecology of Marine Invertebrate Larvae, ed L. R. McEdward (Boca Raton: CRC Press), 1-48.

Levin, L. A., Zhu, J., and Creed, E. (1991). The genetic basis of life-history characters in a polychaete exhibiting planktotrophy and lecithotrophy. Evolution 45, 380-397. doi: $10.2307 / 2409672$

Levins, R. (1969). Some demographic and genetic consequences of environmental heterogeneity for biological control. Bull. ESA 15, 237-240.

Lidicker, W. Z. Jr., and Stenseth, N. C. (1992). "To disperse or not to disperse: who does it and why?," in Animal Dispersal: Small Mammals as a Model, eds L. C. Stenseth and W. Z. Lidicker (Amsterdam: Springer), 21-36.

López-Duarte, P. C., Carson, H. S., Cook, G. S., Fodrie, F. J., Becker, B. J., Dibacco, C., et al. (2012). What controls connectivity? An empirical, multi-species approach. Integr. Comp. Biol. 52, 511-524. doi: 10.1093/icb/ics104

Lowe, W. H., and McPeek, M. A. (2011). Can natural selection maintain longdistance dispersal? Insight from a stream salamander system. Evol. Ecol. 26, 11-24. doi: 10.1007/s10682-011-9500-z

Lowe, W. H., and McPeek, M. A. (2014). Is dispersal neutral? Trends Ecol. Evol. 29, 444-450. doi: 10.1016/j.tree.2014.05.009

Macpherson, E., and Raventos, N. (2005). Settlement patterns and post-settlement survival in two Mediterranean littoral fishes: influences of early-life traits and environmental variables. Mar. Biol. 148, 167-177. doi: 10.1007/s00227-0050059-5

Marshall, D. J. (2008). Transgenerational plasticity in the sea: context-dependent maternal effects across the life history. Ecology 89, 418-427. doi: 10.1890/070449.1

Marshall, D. J., Allen, R. M., and Crean, A. J. (2008). The ecological and evolutionary importance of maternal effects in the sea. Oceanogr. Mar. Biol. An Annu. Rev. 46, 203-250. doi: 10.1201/9781420065756.ch5

Marshall, D. J., Cook, C. N., and Emlet, R. B. (2006). Offspring size effects mediate competitive interactions in a colonial marine invertebrate. Ecology 87, 214-225. doi: 10.1890/05-0350

Marshall, D. J., and Keough, M. J. (2003). Variation in the dispersal potential of non-feeding invertebrate larvae: the desperate larva hypothesis and larval size. Mar. Ecol. Prog. Ser. 255, 145-153. doi: 10.3354/meps255145

Marshall, D. J., and Keough, M. J. (2008). The evolutionary ecology of offspring size in marine invertebrates. Adv. Mar. Biol. 53, 1-60. doi: 10.1016/S00652881(07)53001-4

Marshall, D. J., Monro, K., Bode, M., Keough, M. J., and Swearer, S. (2010). Phenotype-environment mismatches reduce connectivity in the sea. Ecol. Lett. 13, 128-140. doi: 10.1111/j.1461-0248.2009.01408.x

Marshall, D. J., and Morgan, S. G. (2011). Ecological and evolutionary consequences of linked life-history stages in the sea. Curr. Biol. 21, R718-R725. doi: 10.1016/j.cub.2011.09.046
Marshall, D. J., Pechenik, J. A., and Keough, M. J. (2003). Larval activity levels and delayed metamorphosis affect post-larval performance in the colonial ascidian Diplosoma listerianum. Mar. Ecol. Prog. Ser. 246, 153-162. doi: 10.3354/meps246153

Marshall, D. J., and Steinberg, P. D. (2014). Larval size and age affect colonization in a marine invertebrate. J. Exp. Biol. 217, 3981-3987. doi: 10.1242/jeb.111781

Marshall, D., and Uller, T. (2007). When is a maternal effect adaptive? Oikos 116, 1957-1963. doi: 10.1111/j.2007.0030-1299.16203.x

Matter, S. F. (2006). Changes in landscape structure decrease mortality during migration. Oecologia 150, 8-16. doi: 10.1007/s00442-006-0491-3

McCormick, M. I. (1999). Experimental test of the effect of maternal hormones on larval quality of a coral reef fish. Oecologia 118, 412-422. doi: $10.1007 / \mathrm{s} 004420050743$

McCormick, M. I. (2006). Mothers matter: crowding leads to stressed mothers and smaller offspring in marine fish. Ecology 87, 1104-1109. doi: 10.1890/00129658(2006)87[1104:MMCLTS]2.0.CO;2

McCormick, M. I., and Hoey, A. S. (2004). Larval growth history determines juvenile growth and survival in a tropical marine fish. Oikos 106, 225-242. doi: 10.1111/j.0030-1299.2004.13131.x

McDowall, R. M. (2007). On amphidromy, a distinct form of diadromy in aquatic organisms. Fish Fish. 8, 1-13. doi: 10.1111/j.1467-2979.2007.00232.x

McDowall, R. M. (2010). Why be amphidromous: expatrial dispersal and the place of source and sink population dynamics? Rev. Fish Biol. Fish. 20, 87-100. doi: 10.1007/s11160-009-9125-2

Meekan, M. G., Carleton, J. H., McKinnon, A. D., Flynn, K., and Furnas, M. (2003). What determines the growth of tropical reef fish larvae in the plankton: food or temperature? Mar. Ecol. Prog. Ser. 256, 193-204. doi: 10.3354/meps 256193

Meekan, M. G., and Fortier, L. (1996). Selection for fast growth during the larval life of Atlantic cod Gadus morhua on the Scotian Shelf. Mar. Ecol. Prog. Ser. 137, 25-37. doi: 10.3354/meps 137025

Meekan, M. G., von Kuerthy, C., McCormick, M. I., and Radford, B. (2010). Behavioural mediation of the costs and benefits of fast growth in a marine fish. Anim. Behav. 79, 803-809. doi: 10.1016/j.anbehav.2009.12.002

Miller, G. M., Watson, S.-A., Donelson, J. M., McCormick, M. I., and Munday, P. L. (2012). Parental environment mediates impacts of increased carbon dioxide on a coral reef fish. Nat. Clim. Chang. 2, 858-861. doi: 10.1038/nclimate1599

Miner, B. G., Donovan, D. A., and Andrews, K. E. (2010). Should I stay or should I go: predator-and conspecific-induced hatching in a marine snail. Oecologia 163, 69-78. doi: 10.1007/s00442-010-1570-z

Mizrahi, D., Navarrete, S. A., and Flores, A. A. V. (2014). Groups travel further: pelagic metamorphosis and polyp clustering allow higher dispersal potential in sun coral propagules. Coral Reefs 33, 443-448. doi: 10.1007/s00338-014$1135-4$

Monro, K., Sinclair-Taylor, T., and Marshall, D. J. (2010). Selection on offspring size among environments: the roles of environmental quality and variability. Funct. Ecol. 24, 676-684. doi: 10.1111/j.1365-2435.2009.01665.x

Nanninga, G. B., Saenz-Agudelo, P., Manica, A., and Berumen, M. L. (2014). Environmental gradients predict the genetic population structure of a coral reef fish in the Red Sea. Mol. Ecol. 23, 591-602. doi: 10.1111/mec.12623

Nosil, P., Vines, T. H., and Funk, D. J. (2005). Reproductive isolation caused by natural selection against immigrants from divergent habitats. Evolution 59, 705-719. doi: 10.1111/j.0014-3820.2005.tb01747.x

O'Riain, M. J., Jarvis, J. U. M., and Faulkes, C. G. (1996). A dispersive morph in the naked mole-rat. Nature 380, 619-621. doi: 10.1038/380619a0

Oyarzun, F. X., and Strathmann, R. R. (2011). Plasticity of hatching and the duration of planktonic development in marine invertebrates. Integr. Comp. Biol. 51, 81-90. doi: 10.1093/icb/icr009

Palmer, S. C. F., Coulon, A., and Travis, J. M. J. (2014). Inter-individual variability in dispersal behaviours impacts connectivity estimates. Oikos 123, 923-932. doi: 10.1111/oik.01248

Paris, C. B., ChÈrubin, L. M., and Cowen, R. K. (2007). Surfing, spinning, or diving from reef to reef: effects on population connectivity. Mar. Ecol. Prog. Ser. 347, 285-300. doi: 10.3354/meps06985

Paris, C. B., and Cowen, R. K. (2004). Direct evidence of a biophysical retention mechanism for coral reef fish larvae. Limnol. Oceanogr. 49, 1964-1979. doi: 10.4319/lo.2004.49.6.1964

Pechenik, J. A. (2006). Larval experience and latent effects-metamorphosis is not a new beginning. Integr. Comp. Biol. 46, 323-333. doi: 10.1093/icb/icj028 
Pennekamp, F., Mitchell, K. A., Chaine, A., and Schtickzelle, N. (2014). Dispersal propensity in Tetrahymena thermophila ciliates - a reaction norm perspective. Evolution 68, 2319-2330. doi: 10.1111/evo.12428

Perez, K. O., and Munch, S. B. (2010). Extreme selection on size in the early lives of fish. Evolution 64, 2450-2457. doi: 10.1111/j.1558-5646.2010.00994.x

Phillips, N. E. (2004). Variable timing of larval food has consequences for early juvenile performance in a marine mussel. Ecology 85, 2341-2346. doi: 10.1890/03-3097

Pineda, J., Hare, J. A., and Sponaungle, S. (2007). Larval transport and dispersal in the coastal ocean and consequences for population connectivity. Oceanography 20, 22-39. doi: 10.5670/oceanog.2007.27

Pineda, J., Porri, F., Starczak, V., and Blythe, J. (2010). Causes of decoupling between larval supply and settlement and consequences for understanding recruitment and population connectivity. J. Exp. Mar. Bio. Ecol. 392, 9-21. doi: 10.1016/j.jembe.2010.04.008

Pinsky, M. L., Palumbi, S. R., Andréfouët, S., and Purkis, S. J. (2012). Open and closed seascapes: where does habitat patchiness create populations with high fractions of self-recruitment? Ecol. Appl. 22, 1257-1267. doi: 10.1890/111240.1

Planes, S., Jones, G. P., and Thorrold, S. R. (2009). Larval dispersal connects fish populations in a network of marine protected areas. Proc. Natl. Acad. Sci. U.S.A. 106, 5693-5697. doi: 10.1073/pnas.0808007106

Przeslawski, R. (2004). A review of the effects of environmental stress on embryonic development within intertidal gastropod egg masses. Molluscan Res. 24, 43-63. doi: 10.1071/MR04001

Radford, C. A., Jeffs, A. G., and Montgomery, J. C. (2007). Directional swimming behavior by five species of crab postlarvae in response to reef sound. Bull. Mar. Sci. 80, 369-378.

Raimondi, P. T., and Keough, M. J. (1990). Behavioural variability in marine larvae. Aust. J. Ecol. 15, 427-437. doi: 10.1111/j.1442-9993.1990.tb01468.x

Raimondi, P. T., and Morse, A. N. C. (2000). The consequences of complex larval behavior in a coral. Ecology 81, 3193-3211. doi: 10.1890/00129658(2000)081[3193:TCOCLB]2.0.CO;2

Rankin, T. L., and Sponaugle, S. (2011). Temperature influences selective mortality during the early life stages of a coral reef fish. PLOS ONE 6:e16814. doi: 10.1371/journal.pone.0016814

Roff, D. A. (1975). Population stability and the evolution of dispersal in a heterogeneous environment. Oecologia 19, 217-237. doi: 10.1007/BF00345307

Ronce, O. (2007). How does it feel to be like a rolling stone? Ten questions about dispersal evolution. Annu. Rev. Ecol. Evol. Syst. 38, 231-253. doi: 10.1146/annurev.ecolsys.38.091206.095611

Ronce, O., and Clobert, J. (2012). "Dispersal syndromes," in Dispersal Ecoogy and Evolution, eds J. Clobert, M. Baguette, T. G. Benton, and J. M. Bullock (Oxford: Oxford University Press), 119-138.

Rousset, F., and Gandon, S. (2002). Evolution of the distribution of dispersal distance under distance-dependent cost of dispersal. J. Evol. Biol. 15, 515-523. doi: 10.1046/j.1420-9101.2002.00430.x

Saenz-Agudelo, P., Jones, G. P., Thorrold, S. R., and Planes, S. (2011). Connectivity dominates larval replenishment in a coastal reef fish metapopulation. Proc. Biol. Sci. 278, 2954-2961. doi: 10.1098/rspb.2010.2780

Saenz-Agudelo, P., Jones, G. P., Thorrold, S. R., and Planes, S. (2012). Patterns and persistence of larval retention and connectivity in a marine fish metapopulation. Mol. Ecol. 21, 4695-4705. doi: 10.1111/j.1365-294X.2012.05726.x

Saenz-Agudelo, P., Jones, G., Thorrold, S., and Planes, S. (2014). Mothers matter: contribution to local replenishment is linked to female size, mate replacement and fecundity in a fish metapopulation. Mar. Biol. 1-12. doi: 10.1007/s00227014-2556-x

Sale, P. F., Hanski, I., and Kritzer, J. P. (2006). "The merging of metapopulation theory and marine ecology: establishing the historical context," in Marine Metapopulations, eds J. P. Kritzer and P. F. Sale (Burlington, MA: Elsevier Academic Press), 3-23.

Sanford, E., and Kelly, M. W. (2011). Local adaptation in marine invertebrates. Ann. Rev. Mar. Sci. 3, 509-535. doi: 10.1146/annurev-marine-120709-142756

Scholz, A. T., Horrall, R. M., Cooper, J. C., and Hasler, A. D. (1976). Imprinting to chemical cues: the basis for home stream selection in salmon. Science 192, 1247-1249. doi: 10.1126/science. 1273590

Schtickzelle, N., Mennechez, G., and Baguette, M. (2006). Dispersal depression with habitat fragmentation in the bog fritillary butterfly. Ecology 87, 1057-1065. doi: 10.1890/0012-9658(2006)87[1057:DDWHFI]2.0.CO;2
Searcy, S. P., and Sponaugle, S. (2000). Variable larval growth in a coral reef fish. Mar. Ecol. Prog. Ser. 206, 213-226. doi: 10.3354/meps206213

Sekar, S. (2012). A meta-analysis of the traits affecting dispersal ability in butterflies: can wingspan be used as a proxy? J. Anim. Ecol. 81, 174-184. doi: 10.1111/j.13652656.2011.01909.x

Selonen, V., Hanski, I. K., and Mäkeläinen, S. (2012). Predictors of longdistance dispersal in the Siberian flying squirrel. Evol. Ecol. 26, 1361-1369. doi: 10.1007/s10682-012-9569-z

Shima, J. S., Noonburg, E. G., and Phillips, N. E. (2010). Life history and matrix heterogeneity interact to shape metapopulation connectivity in spatially structured environments. Ecology 91, 1215-1224. doi: 10.1890/08-2058.1

Shima, J. S., and Swearer, S. E. (2009). Larval quality is shaped by matrix effects: implications for connectivity in a marine metapopulation. Ecology 90, 1255-1267. doi: 10.1890/08-0029.1

Shima, J. S., and Swearer, S. E. (2010). The legacy of dispersal: larval experience shapes persistence later in the life of a reef fish. J. Anim. Ecol. 79, 1308-1314. doi: 10.1111/j.1365-2656.2010.01733.x

Shulzitski, K. (2012). Population Connectivity in a Dynamic Coastal System: Effects of Mesoscale Eddies on Distribution, Growth, Survival, and Transport of Larval Reef Fishes. PhD Thesis. Available online at: http://scholarlyrepository.miami.edu/oa_dissertations/835/

Simpson, S. D., Munday, P. L., Wittenrich, M. L., Manassa, R., Dixson, D. L., Gagliano, M., et al. (2011). Ocean acidification erodes crucial auditory behaviour in a marine fish. Biol. Lett. 7, 917-920. doi: 10.1098/rsbl. 2011.0293

Smith, A. C., and Shima, J. S. (2011). Variation in the effects of larval history on juvenile performance of a temperate reef fish. Austral Ecol. 36, 830-838. doi: 10.1111/j.1442-9993.2010.02223.x

Sotka, E. E. (2012). Natural selection, larval dispersal, and the geography of phenotype in the sea. Integr. Comp. Biol. 52, 538-545. doi: 10.1093/icb/ics084

Sponaugle, S., Cowen, R. K., Shanks, A., Morgan, S. G., Leis, J. M., Pineda, J., et al. (2002). Predicting self-recuitment in marine populations: biophysical correlates and mechanisms. Bull. Mar. Sci. 70, 341-375.

Sponaugle, S., Grorud-Colvert, K., and Pinkard, D. (2006). Temperature-mediated variation in early life history traits and recruitment success of the coral reef fish Thalassoma bifasciatum in the Florida Keys. Mar. Ecol. Ser. 308, 1-15. doi: $10.3354 /$ meps308001

Stamps, J., a (2006). The silver spoon effect and habitat selection by natal dispersers. Ecol. Lett. 9, 1179-1185. doi: 10.1111/j.1461-0248.2006.00972.x

Stamps, J. A. (2007). Growth-mortality tradeoffs and "personality traits" in animals. Ecol. Lett. 10, 355-363. doi: 10.1111/j.1461-0248.2007.01034.x

Stamps, J. A., Krishnan, V. V., and Reid, M. L. (2005). Search costs and habitat selection by dispersers. Ecology 86, 510-518. doi: 10.1890/04-0516

Stevens, V. M., Pavoine, S., and Baguette, M. (2010). Variation within and between closely related species uncovers high intra-specific variability in dispersal. PLoS ONE 5:e11123. doi: 10.1371/journal.pone.0011123

Stevens, V. M., Trochet, A., Blanchet, S., Moulherat, S., Clobert, J., and Baguette, M. (2013). Dispersal syndromes and the use of life-histories to predict dispersal. Evol. Appl. 6, 630-642. doi: 10.1111/eva.12049

Stevens, V. M., Whitmee, S., Galliard, L., Clobert, J., Böhning-Gaese, K., Bonte, D., et al. (2014). A comparative analysis of dispersal syndromes in terrestrial and semi-terrestrial animals. Ecol. Lett. 17, 1039-1052. doi: 10.1111/ele. 12303

Stobutzki, I. C., and Bellwood, D. R. (1994). An analysis of the sustained swimming abilities of pre-and post-settlement coral reef fishes. J. Exp. Mar. Bio. Ecol. 175, 275-286. doi: 10.1016/0022-0981(94)90031-0

Stobutzki, I. C., and Bellwood, D. R. (1997). Sustained swimming abilities of the late pelagic stages of coral reef fishes. Mar. Ecol. Prog. Ser. 149, 35-41. doi: 10.3354/meps 149035

Strathmann, R. R., Strathmann, M. F., Ruiz-Jones, G., and Hadfield, M. G. (2010). Effect of plasticity in hatching on duration as a precompetent swimming larva in the nudibranch Phestilla sibogae. Invertebr. Biol. 129, 309-318. doi: 10.1111/j.1744-7410.2010.00212.x

Sundelöf, A., and Jonsson, P. R. (2012). Larval dispersal and vertical migration behaviour - a simulation study for short dispersal times. Mar. Ecol. 33, 183-193. doi: 10.1111/j.1439-0485.2011.00485.x

Suthers, I. M. (1998). Bigger? Fatter? Or is faster growth better? Considerations on condition in larval and juvenile coral-reef fish. Aust. J. Ecol. 23, 265-273. doi: 10.1111/j.1442-9993.1998.tb00730.x 
Swearer, S. E., Shima, J. S., Hellberg, M. E., Thorrold, S. R., Jones, G. P., Robertson, D. R., et al. (2002). Evidence of self-recruitment in demersal marine populations. Bull. Mar. Sci. 70, 251-271.

Tarwater, C. E., and Beissinger, S. R. (2012). Dispersal polymorphisms from natal phenotype-environment interactions have carry-over effects on lifetime reproductive success of a tropical parrot. Ecol. Lett. 15, 1218-1229. doi: 10.1111/j.1461-0248.2012.01843.x

Toonen, R. J., and Pawlik, J. R. (1994). Foundations of gregariousness. Nature 370, 511-512. doi: 10.1038/370511a0

Toonen, R. J., and Pawlik, J. R. (2001a). Foundations of gregariousness: a dispersal polymorphism among the planktonic larvae of a marine invertebrate. Evolution 55, 2439-2454. doi: 10.1111/j.0014-3820.2001.tb00759.x

Toonen, R., and Pawlik, J. (2001b). Settlement of the gregarious tube worm Hydroides dianthus (Polychaeta: Serpulidae). I. Gregarious and nongregarious settlement. Mar. Ecol. Prog. Ser. 224, 103-114. doi: 10.3354/meps224103

Tschirren, B., Fitze, P. S., and Richner, H. (2007). Maternal modulation of natal dispersal in a passerine bird: an adaptive strategy to cope with parasitism? Am. Nat. 169, 87-93. doi: 10.1086/509945

Van Allen, B. G., and Rudolf, V. H. W. (2013). Ghosts of habitats past: environmental carry-over effects drive population dynamics in novel habitat. Am. Nat. 181, 596-608. doi: 10.1086/670127

Vendetti, J. E., Trowbridge, C. D., and Krug, P. J. (2012). Poecilogony and population genetic structure in Elysia pusilla (Heterobranchia: Sacoglossa), and reproductive data for five sacoglossans that express dimorphisms in larval development. Integr. Comp. Biol. 52, 138-150. doi: 10.1093/icb/ ics077

Vermeij, M. J. A., Marhaver, K. L., Huijbers, C. M., Nagelkerken, I., and Simpson, S. D. (2010). Coral larvae move toward reef sounds. PLOS ONE 5:e10660. doi: 10.1371/journal.pone.0010660

Vigliola, L., and Meekan, M. G. (2002). Size at hatching and planktonic growth determine post-settlement survivorship of a coral reef fish. Oecologia 131, 89-93. doi: 10.1007/s00442-001-0866-4

Vikebø, F., Jørgensen, C., Kristiansen, T., and Fiksen, Ø. (2007). Drift, growth, and survival of larval Northeast Arctic cod with simple rules of behaviour. Mar. Ecol. Prog. Ser. 347, 207-219. doi: 10.3354/meps06979
Vikebø, F., Sundby, S., Ådlandsvik, B., and Fiksen, Ø. (2005). The combined effect of transport and temperature on distribution and growth of larvae and pelagic juveniles of Arcto-Norwegian cod. ICES J. Mar. Sci. J. du Cons. 62, 1375-1386. doi: 10.1016/j.icesjms.2005.05.017

Webb, T. J. (2012). Marine and terrestrial ecology: unifying concepts, revealing differences. Trends Ecol. Evol. 27, 535-541. doi: 10.1016/j.tree.2012.06.002

White, C., Selkoe, K. A., Watson, J., Siegel, D. A., Zacherl, D. C., and Toonen, R. J. (2010). Ocean currents help explain population genetic structure. Proc. R. Soc. B Biol. Sci. 277, 1685-1694. doi: 10.1098/rspb.2009.2214

Wilson, D. T., and Meekan, M. G. (2002). Growth-related advantages for survival to the point of replenishment in the coral reef fish Stegastes partitus (Pomacentridae). Mar. Ecol. Prog. Ser. 231, 247-260. doi: 10.3354/meps 231247

Zera, A. J., and Denno, R. F. (1997). Physiology and ecology of dispersal polymorphism in insects. Annu. Rev. Entomol. 42, 207-230. doi: 10.1146/annurev.ento.42.1.207

Zhang, X. (2006). The phenotypic variance within plastic traits under migration-mutation-selection balance. Evolution 60, 1125-1136. doi: 10.1111/j.0014-3820.2006.tb01192.x

Conflict of Interest Statement: The authors declare that the research was conducted in the absence of any commercial or financial relationships that could be construed as a potential conflict of interest.

Received: 17 August 2014; accepted: 19 November 2014; published online: 08 December 2014.

Citation: Nanninga GB and Berumen ML (2014) The role of individual variation in marine larval dispersal. Front. Mar. Sci. 1:71. doi: 10.3389/fmars.2014.00071

This article was submitted to Marine Ecosystem Ecology, a section of the journal Frontiers in Marine Science.

Copyright (C) 2014 Nanninga and Berumen. This is an open-access article distributed under the terms of the Creative Commons Attribution License (CC BY). The use, distribution or reproduction in other forums is permitted, provided the original author(s) or licensor are credited and that the original publication in this journal is cited, in accordance with accepted academic practice. No use, distribution or reproduction is permitted which does not comply with these terms. 